\title{
Assessing the influence of legal constraints on the integration of renewable energy technologies in polygeneration systems for buildings
}

\author{
Eduardo A. Pina ${ }^{a, b, *}$, Miguel A. Lozano a ${ }^{\text {, Luis M. Serra }}{ }^{\text {a }}$ \\ ${ }^{a}$ Group of Thermal Engineering and Energy Systems (GITSE) of Aragon Institute of \\ Engineering Research (I3A), Department of Mechanical Engineering, University of Zaragoza, \\ Calle María de Luna 3, Zaragoza 50018, Spain. \\ ${ }^{\mathrm{b}}$ University Center of Defense (CUD), Academia General Militar, Ctra. de Huesca s/n, \\ Zaragoza 50090, Spain. \\ * corresponding author \\ E-mail addresses: epina@unizar.es (E.A. Pina), mlozano@unizar.es (M.A. Lozano), \\ serra@unizar.es (L.M. Serra).
}

\begin{abstract}
Hybrid polygeneration systems offer a great opportunity to meet growing energy demands with cost efficiency and environmental benefits. The identification of the optimal solution (configuration and operational strategy) is strongly affected by the relationship between the system and its surroundings. Previous studies have analyzed the influence of boundary conditions on the synthesis of polygeneration systems for buildings. However, local regulations are often disregarded or oversimplified in those studies. Therefore, this paper aims to evaluate the influence of legal conditions on the integration of renewable energy technologies in polygeneration systems for buildings. A comprehensive synthesis model is developed, including different types of legal conditions, such as power exchange modalities, subsidies/surcharges on energy prices and investment costs, and total ban on fossil fuels. Then, the model is applied to the case study of a Brazilian hospital. The current Brazilian net metering scheme is implemented. Results show that natural gas cogeneration is an attractive solution to cover the hospital's energy demands with or without the possibility of selling/exporting electricity. Also, the Brazilian net metering scheme, by itself, is not enough to ensure renewable energy deployment. An in-depth discussion about the conditions that would promote renewable energy integration is reported and recommendations are made on how current policies can be improved, including the need to explicitly address renewable technologies, the application of minimum renewable fractions, and the role of renewable heat/cooling. While the case study considers the specific circumstances in Brazil, it provides insights that can be extended to other countries or applications.
\end{abstract}

\section{Highlights}

- Synthesis model of hybrid renewable polygeneration systems for buildings

- Influence of legal constraints on the integration of renewable energy technologies

- Power exchange modalities, subsidies/surcharges, and fossil fuel ban are considered

- Technical, economic, and environmental analysis of a Brazilian hospital case study

- The Brazilian net metering scheme did not promote renewable energy technologies 
Keywords: Buildings, hospital; legal constraint; MILP; polygeneration; renewable energy; sensitivity analysis.

Word Count: 14198 words.

\section{Nomenclature}

\section{$\underline{\text { Abbreviations and acronyms }}$}

$\begin{array}{ll}\text { AD } & \text { Double-effect absorption chiller } \\ \text { ANEEL } & \text { Brazilian Electricity Regulatory Agency } \\ \text { AS } & \text { Single-effect absorption chiller } \\ \text { BH } & \text { Biomass hot water boiler } \\ \text { BV } & \text { Biomass steam boiler } \\ \text { CCHP } & \text { Combined Cooling, Heat and Power } \\ \text { CHP } & \text { Combined Heat and Power } \\ \text { COP } & \text { Coefficient of Production } \\ \text { CS } & \text { Chilled water storage tank } \\ \text { CT } & \text { Cooling tower } \\ \text { DG } & \text { Distributed generation } \\ \text { EC } & \text { Mechanical chiller } \\ \text { EECS } & \text { Electrical Energy Compensation System } \\ \text { FIT } & \text { Feed-In-Tariff } \\ \text { GE } & \text { Cogeneration module } \\ \text { GH } & \text { Natural gas hot water boiler } \\ \text { GV } & \text { Natural gas steam boiler } \\ \text { HS } & \text { Hot water storage tank } \\ \text { HTF } & \text { Heat Transfer Fluid } \\ \text { LHV } & \text { Lower Heating Value } \\ \text { MILP } & \text { Mixed Integer Linear Programming } \\ \text { NR } & \text { Normative Resolution } \\ \text { PM } & \text { Prime Mover } \\ \text { PT } & \text { Parabolic trough concentrator } \\ \text { PV } & \text { Photovoltaic Panel } \\ \text { RES } & \text { Renewable Energy Sources } \\ \text { RET } & \text { Renewable Energy Technology } \\ \text { SAM } & \text { System Advisor Model } \\ \text { ST } & \text { Flat-plate solar thermal collector } \\ \text { TES } & \text { Thermal Energy Storage } \\ \text { wd } & \text { Working day } \\ \text { we } & \text { Weekend } \\ & \end{array}$

$\underline{\text { Symbols }}$
$A_{m, p v} \quad$ Module surface area, $\mathrm{m}^{2}$
CI Bare module cost, $€ / \mathrm{kW}$
$\mathrm{CO}_{\text {bio }} \quad \mathrm{CO}_{2}$ emissions of biomass consumption, $\mathrm{kg} \mathrm{CO}_{2} / \mathrm{yr}$
$\mathrm{CO}_{\text {ele }} \quad \mathrm{CO}_{2}$ emissions of electricity consumption, $\mathrm{kg} \mathrm{CO}_{2} / \mathrm{yr}$ 
$\mathrm{CO}_{\text {fix }} \quad$ Annual fixed $\mathrm{CO} 2$ emissions, $\mathrm{kg} \mathrm{CO}_{2} / \mathrm{yr}$

$\mathrm{CO} 2_{\text {gas }} \quad \mathrm{CO}_{2}$ emissions of natural gas consumption, $\mathrm{kg} \mathrm{CO}_{2} / \mathrm{yr}$

$\mathrm{CO} 2_{\text {tot }} \quad$ Total annual $\mathrm{CO}_{2}$ emissions, $\mathrm{kg} \mathrm{CO}_{2} / \mathrm{yr}$

$\mathrm{CO} 2 \mathrm{U} \quad$ Unit $\mathrm{CO}_{2}$ emissions $\mathrm{CO} 2 \mathrm{U}, \mathrm{kg} \mathrm{CO}_{2} / \mathrm{kW}_{\text {nom }}$

$\mathrm{CO} 2_{\text {var }}$ Annual variable $\mathrm{CO}_{2}$ emissions, $\mathrm{kg} \mathrm{CO} / \mathrm{yr}$

$C T E_{\text {bio }} \quad$ Biomass consumption cost, $€ / \mathrm{yr}$

$C T E_{\text {ele }} \quad$ Electricity consumption cost, $€ / \mathrm{yr}$

$C T E_{f i x} \quad$ Annual fixed cost, $€ / y r$

$C T E_{\text {gas }} \quad$ Natural gas consumption cost, $€ / \mathrm{yr}$

$C T E_{\text {tot }} \quad$ Total annual cost, $€ /$ yr

$C T E_{\text {var }} \quad$ Annual operation cost, $€ / \mathrm{yr}$

CUe Unit auxiliary electricity consumption, $\mathrm{kW}_{\mathrm{el}} / \mathrm{kW}$

$E_{d} \quad$ Electricity demand, $\mathrm{kW}$

$E E E_{-} Y \quad$ Annual equivalent electric efficiency, \%

$E_{\text {exp }} \quad$ Exported electricity, $\mathrm{kW}$

$E_{i m p} \quad$ Imported electricity, $\mathrm{kW}$

$E_{p} \quad$ Electricity purchased from the grid, $\mathrm{kW}$

$E_{s} \quad$ Electricity sold to the grid, $\mathrm{kW}$

fam Amortization and maintenance factor, $\mathrm{yr}^{-1}$

$F_{b h} \quad$ Natural gas consumption by the BH, kW

$F_{b v} \quad$ Natural gas consumption by the BV, kW

$F_{g e} \quad$ Natural gas consumption by the engine, $\mathrm{kW}$

$F_{g h} \quad$ Natural gas consumption by the GH, kW

$F_{g v} \quad$ Natural gas consumption by the GV, kW

$f_{I C} \quad$ Indirect costs factor, -

$k_{l} \quad$ Thermal coefficient, $\mathrm{W} /\left(\mathrm{m}^{2} \cdot \mathrm{K}\right)$

$k_{2} \quad$ Thermal coefficient, $\mathrm{W} /\left(\mathrm{m}^{2} \cdot \mathrm{K}^{2}\right)$

$\mathrm{kgCO} 2_{\text {bio }}$ Biomass $\mathrm{CO}_{2}$ emission factor, $\mathrm{kg} \mathrm{CO}_{2} / \mathrm{kWh}$

$\mathrm{kgCO} 2_{\text {ele }}$ Grid electricity $\mathrm{CO}_{2}$ emission factor, $\mathrm{kg} \mathrm{CO}_{2} / \mathrm{kWh}$

$\mathrm{kgCO} 2_{\text {gas }}$ Natural gas $\mathrm{CO}_{2}$ emission factor, $\mathrm{kg} \mathrm{CO}_{2} / \mathrm{kWh}$

NHP Number of hours per period

$N R Y \quad$ Number of representative days type $d$ per year

nyr Operational lifetime of the plant, yr

$p_{\text {bio }} \quad$ Biomass purchase price, $€ / \mathrm{kWh}$ (LHV)

penven Penalization for the electricity selling price, $€ / \mathrm{kWh}$

$p_{e p} \quad$ Electricity purchase price, $€ / \mathrm{kWh}$

$p_{e s} \quad$ Electricity selling price, $€ / \mathrm{kWh}$

$p_{\text {gas }} \quad$ Natural purchase price, $€ / \mathrm{kWh}$ (LHV)

PIN Installed capacity of technology $t, \mathrm{~kW}$

$P_{\text {INAX }} \quad$ Maximum installable capacity of technology $\mathrm{t}, \mathrm{kW}$

$P_{p v} \quad$ Maximum power, $\mathrm{kW}$

$Q_{a c} \quad$ Charge air heat, $\mathrm{kW}$

$Q_{a d} \quad$ Heat consumed by the AD, kW

$Q_{a s} \quad$ Heat consumed by the AS, kW

$Q_{b h} \quad$ Heat produced by the BH, kW

$Q_{B n} \quad$ Monthly mean hourly normal direct solar radiation, $\mathrm{kW} / \mathrm{m}^{2}$

$Q_{b v} \quad$ Heat produced by the BV, $\mathrm{kW}$

$Q_{d} \quad$ Hot water demand, $\mathrm{kW}$ 


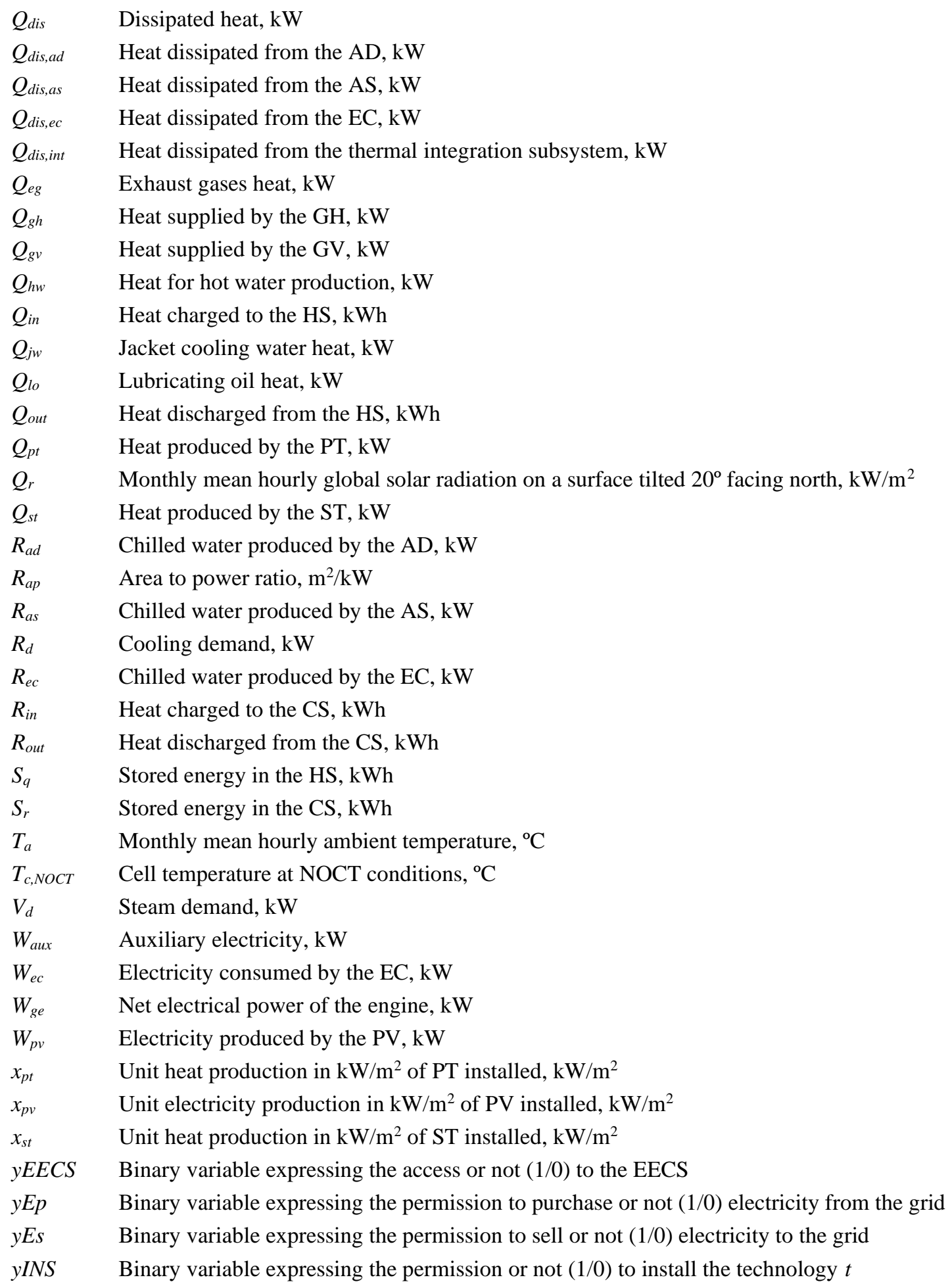

$\underline{\text { Indices }}$

$\begin{array}{ll}d & \text { Representative day } \\ h & \text { Hourly period } \\ t & \text { Technology }\end{array}$

$\underline{\text { Greek letters }}$ 


$\begin{array}{ll}\mu_{T} & \text { Temperature coefficient of power } \\ \eta & \text { Total energy efficiency, } \% \\ \eta_{0} & \text { Thermal coefficient } \\ \eta_{q} & \text { Heat efficiency, } \% \\ \eta_{w} & \text { Electrical efficiency, } \%\end{array}$

\section{Introduction}

\subsection{Energy systems optimization to support decision-making}

Decarbonizing the buildings sector is a key step toward meeting global climate and energy targets. Residential, commercial, and public buildings account for about a third of the world's final energy consumption and about half of the world's final electricity consumption [1]. In addition, the share of electricity in the total energy use in buildings is projected to increase from $21 \%$ in 2018 to $38 \%$ in 2050 [2]. Space cooling is the fastest-growing end use in buildings and one of the major drivers of global electricity consumption, having more than tripled since 1990 [3], it is also expected to continue rising in the next decades promoted by population growth, rising household income, cheaper air conditioning units, as well as more frequent events of extreme temperatures [4,5].

Conventionally, electricity is generated by a centralized power system and supplied to buildings through distribution networks, while heating and cooling demands are covered by individual production at the consumer level through gas boilers, electric heaters, vapor compression chillers, among others. By contrast, cogeneration (Combined Heat and Power, CHP) and trigeneration (Combined Cooling, Heat and Power, CCHP) systems [6,7] can be located close to or at end-users, providing electricity and thermal energy with higher energy efficiency, reduced environmental impacts, and lower unit costs of the final products thanks to an appropriate process integration [8]. Other benefits of such distributed generation (DG) include [9,10]: (i) flexibility and peak shaving; (ii) enhanced reliability and energy security; (iii) reduced costs and energy losses associated with transmission and distribution systems; (iv) lower pollutant emissions; and (v) use of locally available resources and cheap fuel opportunities.

CHP and CCHP fit into the broader concept of polygeneration, which can be generally defined as the combined production of two or more energy services from a common energy resource. Polygeneration systems are regarded as key solutions for the development of sustainable energy systems [11,12] owing to a considerable flexibility of energy resources consumed, technology options employed, and energy services produced. The interest of those systems for buildings of different sizes and applications has been demonstrated in the literature. Specifically, primary energy savings of about $26 \%$ were obtained when installing a gas engine CCHP system for a hospital in Brazil [13]. A total annual cost reduction of about $30 \%$ was achieved for a CCHP system relative to a conventional system for a hospital in Spain [14]. In a neighborhood of office and residential buildings in China, total annual costs were reduced by $15 \%$ and total annual $\mathrm{CO}_{2}$ emissions were cut by $45 \%$ relative to a reference system [15]. For the district heating and cooling system that attends 5000 dwellings in Spain, primary energy consumption was reduced by $70 \%$ in the case of $\mathrm{CHP}$ and $78 \%$ in the case of 
CCHP [8]. The literature generally agrees that substantial energy, economic, and environmental benefits can be achieved by using a properly integrated energy system instead of conventional energy supply systems.

In addition to high-efficiency energy systems, renewable energy sources clearly play a fundamental role in sustainable energy systems. Renewable energy technologies (RETs) based on solar (e.g. photovoltaic panel, solar thermal collector, hybrid photovoltaic/thermal collector), wind (e.g. wind turbine) and biomass (e.g. biomass boiler) are increasingly being integrated in hybrid and renewable polygeneration systems [16]. For residential and commercial applications, natural gas internal combustion engine is the most mature and wellestablished prime mover technology [17]. In this context, combining the dispatchable gas engine with a variable RET has been shown to enhance the overall energy, economic and environmental performances of the system [18], as the two can be used in a complementary way [19]: the RET reduces fossil fuel consumption, while the gas engine ensures a reliable and efficient energy supply.

Therefore, distributed polygeneration systems hybridized with RETs for residential and tertiary sector buildings offer a great opportunity to align the objectives of diversifying the energy supply, while also meeting the growing energy demands close to the consumer center, with cost efficiency and low pollutant emissions. However, to fully exploit all the benefits of polygeneration, a robust and comprehensive synthesis and operation optimization procedure is required [20,21]. Determining the best combination of technologies, their installed capacities, and operating strategy is a complex task. To this end, an effective strategy consists in the preliminary definition of a superstructure containing all feasible combinations of candidate technologies from which the system configuration will be derived after an optimization procedure that minimizes or maximizes an objective function. A thorough review of mathematical optimization approaches for synthesis of energy systems can be found in Andiappan [22] and, with a particular focus on polygeneration systems for buildings, in Rong and $\mathrm{Su}[23]$.

Just as important as the superstructure definition is the accurate representation of the environment within which the system is going to operate. Such environment constitutes the boundary conditions of the problem, which typically involve a variety of parameters such as plant and user characteristics, building types, climatic data, energy resources prices, investment costs of equipment, financial conditions, and regulatory aspects [24]. For this reason, the optimal solution will be not only unique to the problem addressed and to the assumptions made but will also change in the likely event that any of those parameters are different. In other words, the synthesis solution is always time-based and site-specific.

In fact, there is an inherent uncertainty level in the deterministic definition of the input parameters that constitute the boundary conditions of the synthesis problem [25], including unpredictable variations in energy demands (daily and hourly demand profiles, peak demand times), economic (energy prices, investment costs, interest rates), environmental (solar resource availability, ambient temperatures), and regulatory (electric grid regulations, support policies) aspects, to name a few examples. Therefore, an accurate identification of the most relevant model parameters and boundary conditions is an intrinsic part of the optimization 
problem, and, once the optimal solution is determined, it is important to assess the extent to which it is influenced by variations in those conditions [26]. Only then the synthesis procedure can be regarded as an effective tool for decision making.

The influence of boundary conditions on the synthesis of hybrid and renewable polygeneration systems for buildings has been extensively evaluated in the literature. Most studies consider the effect of energy demands [27,28], economic costs [27-29], different types of buildings [19,30], and/or different climate zones [19,25,31]. An interesting study by Noussan and Jarre [32] used real energy price values, primary energy factors, and emission factors of electricity generation in different European Union countries. It can be concluded from those papers that the identification of the optimal solution (system configuration and operational strategy over time) is strongly affected by the relationship between the system and its surroundings. The need for detailed considerations of boundary conditions is thus made clear.

The issue is that, when it comes to the local regulations, they are often neglected or oversimplified, leaving out relevant site-specific details. This paper focuses particularly on the effect of legal aspects on the optimal synthesis of polygeneration systems hybridized with RETs for buildings. Therefore, this issue will be further addressed in the following section.

\subsection{Legal constraints in the synthesis of energy systems for buildings}

Many different policies have been implemented around the world at the national or state level to promote the installation of hybrid and renewable polygeneration systems for buildings, as reviewed by Ropenus et al. [33] for DG systems, De Boeck et al. [34] for residential photovoltaic systems, Aquila et al. [35] for renewable energy generation, and Rickerson et al. [36] for renewable energies in developing countries. Several categories of policies can be found in the literature, such as financial and regulatory [37], investment and operational [33], and indirect and direct [34]. In general, investment policies include capital grants, rebate programs, subsidies, loans, and tax incentives (credits, deductions, and exemptions). As for operational support, there is a distinction between quantity-based schemes, such as quota systems and green certificates, and price-based schemes, such as feed-in tariffs (FiTs) and feed-in premiums. Moreover, some regulatory policies consist of energy efficiency directives, renewable fraction obligations, minimum equivalent electric efficiency, ban on fossil fuels consumption as well as net metering and net billing modalities.

It is important to note that those policies will shape the implemented energy systems, as well as drive market development, by promoting some technologies and hindering others, imposing a particular operational strategy, and affecting the economic profitability and the technical feasibility of the systems. Moreover, the designed energy system must comply with local regulations, otherwise its installation will not be warranted. Besides, regulatory changes are very likely to happen during the operational lifetime of the plant, so that understanding how those changes would affect the system performance provides a better insight into the long-term viability of the plant. Therefore, from the investor's perspective, a realistic scenario that includes all relevant policies is essential to making informed decisions. 
Another important factor to consider is that those policies are always designed to achieve a particular goal, such as a rebate program to foster deployment of RETs, or a ban on fossil fuels to reduce greenhouse gas emissions. It should not come as a surprise that sometimes energy policies produce different, or even opposite, effects to the one intended. For instance, Piacentino et al. [38] identified that an excessive fuel tax exemption for CCHP systems enabled the operation of the cogeneration module as a power unit, so that the system maximized electricity production to the detriment of a more rational use of the cogenerated heat. Therefore, from the policy-maker's perspective, it is crucial to understand the extent to which the proposed objectives are actually being achieved to make the necessary adjustments. In this context, integrated synthesis and operation optimization models are especially useful for a quantitative assessment of the technical, economic, and environmental feasibility of energy systems.

The effect of local regulations on the technical and economic viability of energy systems has been extensively reported in the literature. However, most studies focus on how a specific support scheme affects a particular type of energy system. For instance, residential PV systems have been analyzed in Portugal under four electric grid scenarios [39], in South Africa under a new FiT scheme [40], and in Italy with electricity storage systems under a net metering mechanism [41]. A microturbine for a manufacturing process [42] and a landfill biogas engine coupled with PV systems [43] have been proposed for electricity production under the Brazilian net metering scheme. A rebate program and a time-of-use tariff have been considered to promote solar domestic hot water heating systems in Brazil [44]. While interesting analyses can be made about the effectiveness of regulatory actions aimed to support a particular system or technology, approaching the influence of legal restrictions from the superstructure-based synthesis perspective allows for the identification of potential synergies and competitions between technologies.

Concerning the optimal design of energy systems with local regulations considerations, the FiT is among the most studied mechanisms for a variety of applications, including hospitals [45-47], municipality buildings [48], district heating and cooling networks [49], cities [50], and even regions [51]. Other legal conditions have been identified, such as fuel tax exemption [38], self-consumption obligation and minimum equivalent electrical efficiency [52], carbon tax [50], and a premium scheme [51]. This suggests that many studies focus exclusively on electric grid policies, giving too much attention to the electricity generation side. This issue is not exclusive to researchers, since, as recognized by IRENA [37], most policy attention is dedicated to renewable electricity. However, in highly integrated polygeneration systems the thermal and electrical parts cannot be isolated.

Overall, research on the synthesis of hybrid renewable polygeneration systems for buildings with detailed considerations of legal conditions is quite rare. Two of the most interesting and thorough contributions are commented as follows. Schütz et al. [53] proposed an optimization model for the design, sizing and operation of energy systems supplying electricity and heat to residential buildings with a precise modelling of many specific German regulations, such as feed-in limitation and remuneration, levies, tax exemptions, subsidies, among others. Pinto et al. [54] presented a detailed synthesis model for CCHP systems in residential buildings 
including PV and wind turbines and used the model to compare different Spanish grid regulations.

\subsection{Objectives and contributions}

The literature survey has revealed that legal aspects are often disregarded in energy systems design optimization and analysis studies, particularly in the case of hybrid and renewable polygeneration systems. Moreover, little attention is paid to the integration between thermal and electrical parts in the polygeneration system, which cannot be isolated from each other. Many research contributions focus almost exclusively on electricity production, particularly PV-based. Understanding the thermal-electrical interaction is crucial to achieving the benefits of polygeneration as well as of RETs. Another challenge concerns the careful representation of local regulations, which are often generalized, leaving out relevant site-specific aspects that only apply to that place and moment. The effects of regulation changes need to be investigated in order to grasp the long-term viability and profitability of energy systems as regards the energy transition and carbon neutrality goals.

In this context, the objective of this work is to evaluate the effect of legal conditions on the integration of RETs in polygeneration systems for buildings. To this end, a comprehensive synthesis optimization model has been developed. Relative to previous work, the major contributions of the present study include:

- Extend the mixed integer linear programming (MILP) optimization model presented in a previous study by the authors [55] to include a diverse set of RETs based on solar energy (PV, and flat-plate and parabolic trough collectors) and biomass (biomass boilers). Natural gas cogeneration module, mechanical and absorption chillers, and TES units are also considered.

- Implementation of various types of legal conditions, such as (i) general and localbased modalities of power exchange with the grid; (ii) subsidies and surcharges on energy resources prices; (iii) subsidies to reduce the investment costs of RETs; and (iv) total ban on fossil fuel consumption. Additionally, the effect of considering different $\mathrm{CO}_{2}$ emission factors of the grid electricity is assessed.

- Analyze how different legal conditions will affect RETs deployment and provide insights about how current policies can be improved.

- Identify synergies and competitions between thermal and electrical technologies within the polygeneration system, especially under policy constraints.

It is also worth noting that the synthesis model implemented in the present study incorporates: (i) a detailed modelling of the solar RETs, which takes into account the effect of their working temperatures and environmental conditions (i.e. time-based solar radiation and ambient temperature) on their performances, as opposed to common studies that consider constant efficiencies and average daily values; (ii) real time-dependent $\mathrm{CO}_{2}$ emission factors of the electricity available in the Brazilian power grid, as opposed to simplified studies that consider annual average values; and (iii) the environmental criterion in terms of the $\mathrm{CO}_{2}$ emissions associated with the installation and operation of the system, so that the effects of 
legal conditions can be assessed from the environmental viewpoint as well as from the economic perspective.

Then, the model is applied to the case study of a hospital building in Brazil. Apart from the three general grid exchange modalities (i.e. purchase only, annual consumer, and unrestricted sale), the specific Brazilian net metering scheme is modelled. Thus, the synthesis model presented herein is intended to support researchers and policy makers in identifying and understanding the effects of local regulations on the deployment of RETs in polygeneration systems. The procedure allows the decision maker to evaluate which policies are the most appropriate to achieve the established goals and at what cost.

\section{Materials and methods}

\subsection{Synthesis framework}

The synthesis model is built around an objective function including economic (minimize total annual costs), environmental (minimize total annual $\mathrm{CO}_{2}$ emissions), and energy (maximize primary energy savings) criteria, to name a few. The definition of the superstructure requires a proper assessment of the energy resources (renewable and non-renewable) that are available to the system, the energy products (e.g. electricity, space heating, domestic hot water, chilled water) that are required by the building, and the complex interactions between the candidate technologies (generation, transformation, and storage devices).

The synthesis model developed herein will be used to assess the technical, economic, and environmental feasibility of renewable-based polygeneration systems. The simulation has been performed for the period of one year, which is described by 24 representative days $d$ (one working day and one weekend/holiday for each month of the year), each composed of 24 consecutive periods $h$ of 1-hour duration, resulting in 576 time steps. The remainder of this section describes the main data of the case study, which can be found in detail in Pina [55,56]. A graphical representation of the procedure followed throughout Sections 2 and 3 is depicted in Figure 1.

\subsection{The case study: University hospital in Campinas}

There is a great potential for the application of polygeneration systems in hospitals given their long operating hours, regular occupancy rate, high thermal energy requirements, and varied consumption of energy services (e.g. electricity, steam, hot water, space heating, space cooling) [14,57,58]. Moreover, there is an increasing interest in the need to ensure the quality and reliability of power supply, not only as regards maintaining life critical loads, but also the operation of the entire facility. Nevertheless, polygeneration systems do not eliminate the need for emergency generators, although they can contribute to reducing their installed capacities and numbers [59]. 


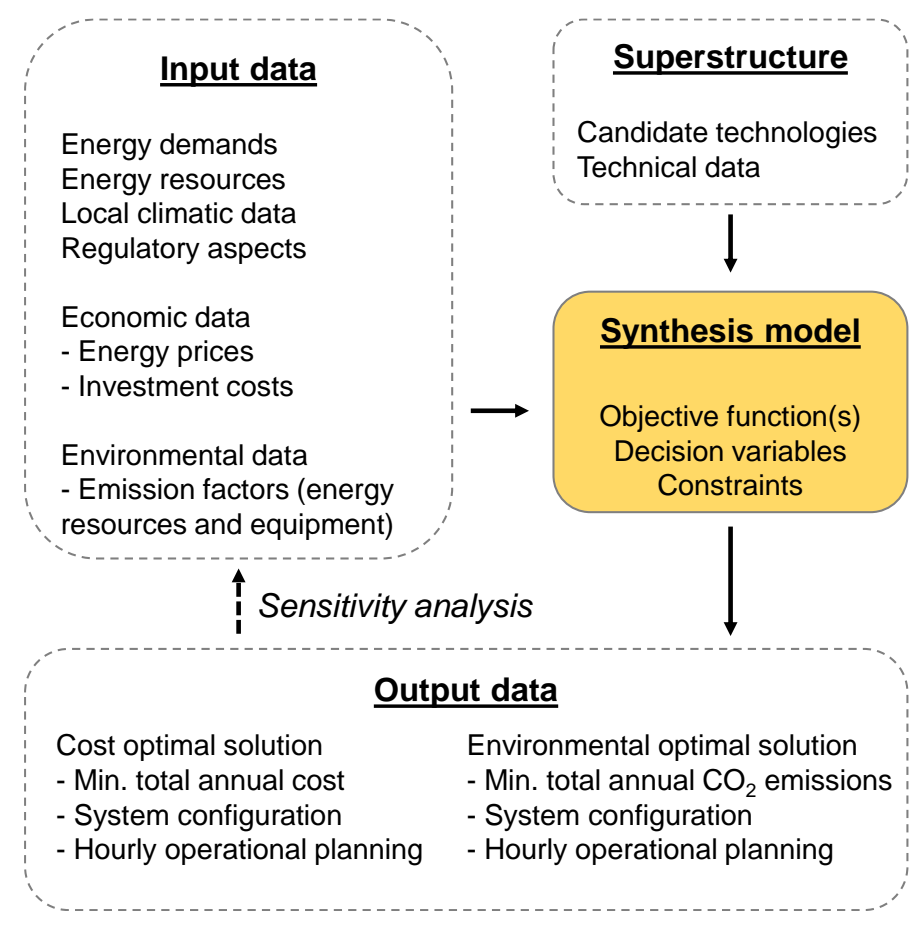

Figure 1: Synthesis procedure.

More particularly, the cogeneration potential in Brazilian hospitals has been analyzed by Szklo et al. [60], who have also identified implementation obstacles inherent to the Brazilian hospital sector. Presently, this situation is changing as new factors are taken into account, such as the normative for power exchange with the grid [61], the decreasing investment costs of photovoltaic panels and solar thermal collectors, subsidies to the price of natural gas for cogeneration purposes, and the increased opportunities for biomass.

The case study presented herein consists of a hospital facility located at the campus of the University of Campinas (UNICAMP), in the city of Campinas, southeast Brazil. The Hospital das Clínicas (latitude $-22.82^{\circ}$, longitude $-47.06^{\circ}$ ) has a constructed area of $65,000 \mathrm{~m}^{2}$, distributed between seven interconnected building blocks of six floors each. The first building was opened in 1979, and the whole complex was finished in 1985. The hospital has 403 beds, 15 operating rooms, a restaurant, two amphitheaters, and many laboratories, classrooms, and meeting rooms [62].

\subsubsection{Energy demands}

The energy demand profiles of the hospital have been obtained from Santo [13]. According to the author, a data acquisition system was installed at the hospital to monitor and register the energy demands at 1-hour intervals. The hospital's energy demands consist of electricity for lighting and elevators (excludes consumption for thermal energy production, such as electricity to produce cooling in electrically driven mechanical chillers); saturated steam (180 ${ }^{\circ} \mathrm{C}$ ) for cooking, laundry and sterilization; hot water $\left(60^{\circ} \mathrm{C}\right)$ for sanitary purposes; and chilled water $\left(7^{\circ} \mathrm{C}\right)$ for air conditioning. Their annual values are 9,633.5 MWh of electricity, 4,660.3 MWh of steam, 518.7 MWh of hot water, and 4,660.3 MWh of chilled water. Hourly profiles are available for a working day and a weekend in each season, as shown in Figure 2: summer 
(January-March), autumn (April-June), winter (July-September), and spring (OctoberDecember). In this way, the representative days of each month within the same season are considered to have the same hourly profiles.
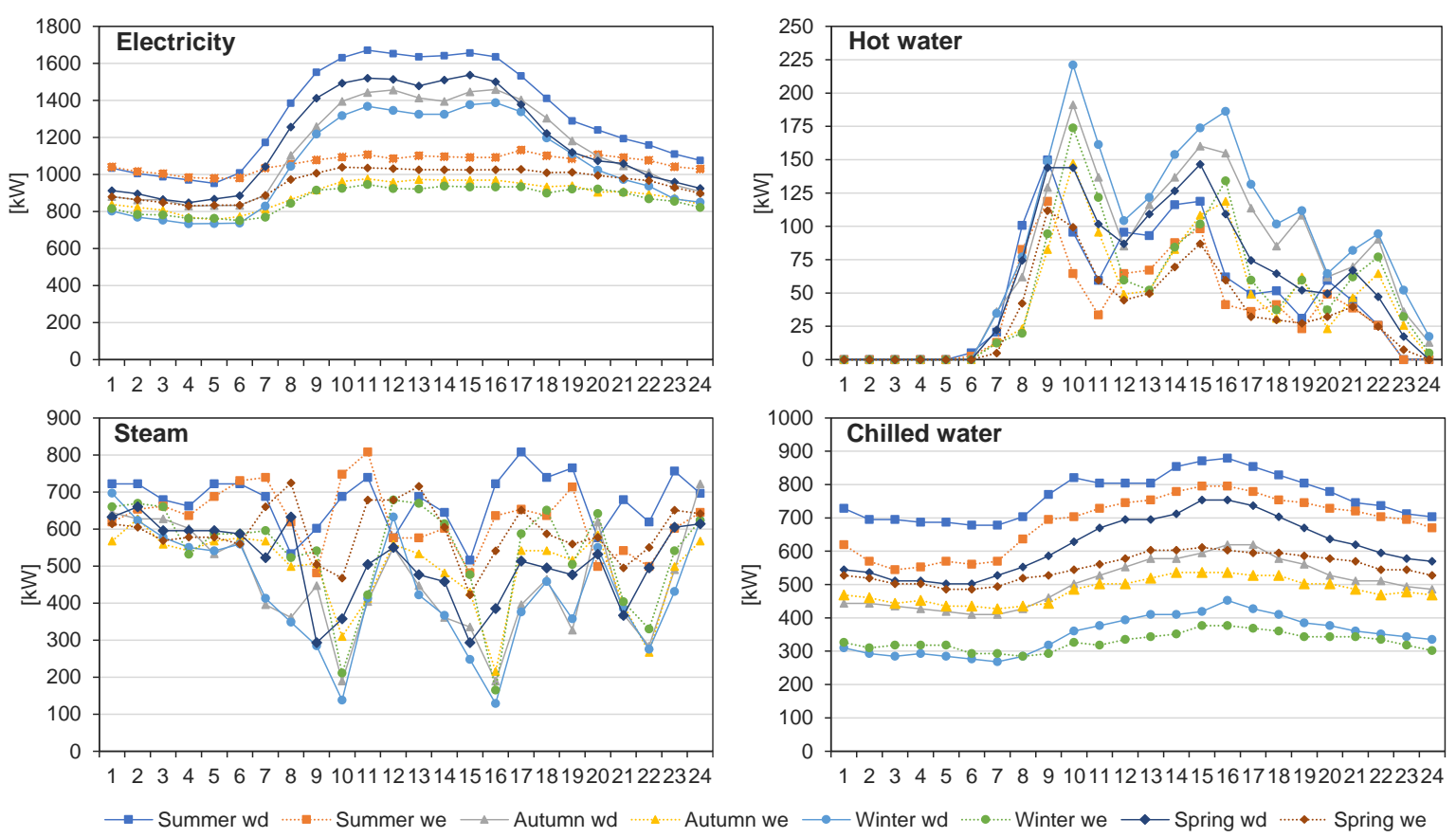

Figure 2: Hourly energy demands of each working day $w d$ and weekend we. Adapted from Santo [13].

\subsubsection{Local climatic data}

Climatic data for the geographical location of Campinas was obtained from the software METEONORM [63]. This information includes the monthly mean hourly ambient temperature $T_{a}$, the monthly mean hourly global solar radiation on a surface tilted $20^{\circ}$ facing north $Q_{r}$, and the monthly mean hourly normal direct solar radiation $Q_{B n}$.

\subsubsection{Economic and environmental data of the fuels and electricity}

For the economic and environmental assessment, the energy resources consumed by the system must be properly characterized in terms of their market-based energy prices and $\mathrm{CO}_{2}$ emission factors. The energy resources available to the system are solar radiation, biomass pellets, natural gas, and electricity from the national electric grid.

Natural gas is purchased at $p_{\text {gas }}=0.035 € / \mathrm{kWh}$ (LHV) [64]. In the case of electricity, a timeof-use tariff applies, consisting of two pricing periods in which the purchase price $p_{e p}$ varies according to the hour of the day and the month of the year. On-peak $p_{e p}=0.136 € / \mathrm{kWh}$ and off-peak $p_{e p}=0.094 € / \mathrm{kWh}$ [65]. The on-peak period takes place between hours 18 and 20 from March to October, and between hours 19 and 21 from November to February. The remaining hours correspond to off-peak periods. It is assumed that electricity can be sold at a price $p_{e s}$ calculated as the $p_{e p}$ at the corresponding hour minus a discount (penalization) of penven $=0.012 € / \mathrm{kWh}$ relative to distribution and availability costs (tariff of use of distribution system) [65]. Finally, the purchase price of biomass pellets was $p_{b i o}=0.026$ 
$€ / \mathrm{kWh}$ (LHV) [66]. The aforementioned energy prices include taxes. The tariffs have been converted from Brazilian Real (BRL) to Euro (EUR) using the reference exchange rate 0.26 EUR/BRL in January 2018, obtained from the Central Bank of Brazil currency conversion tool.

In terms of $\mathrm{CO}_{2}$ emissions, the environmental impact associated with the energy resources consumption is assessed through the $\mathrm{CO}_{2}$ emission factors: (i) natural gas $\mathrm{kgCO} 2_{\text {gas }}=0.2020$ $\mathrm{kg} \mathrm{CO} / \mathrm{kWh}$ [67]; (ii) biomass pellets $\mathrm{kgCO} 2_{\text {bio }}=0.0506 \mathrm{~kg} \mathrm{CO}_{2} / \mathrm{kWh}^{2} 66$ ]; and (iii) electricity in the national electric grid $\mathrm{kgCO} 2$ ele. The $\mathrm{CO}_{2}$ emission factors of the electricity in Brazil's power grid are available on hourly basis for complete yearly periods since 2006 on the website of the Ministry of Science, Technology, Innovations and Communications [68]. We have processed the annual data composed of 8760 hourly periods to obtain the average hourly $\mathrm{CO}_{2}$ emissions for each month of the year, which correspond to the representative days considered in the model, shown in Figure 3 [56]. Working days and weekends of each month were assumed to have the same hourly profiles.

\subsubsection{Electricity and natural gas regulations in Brazil}

A realistic representation of the case study must also consider local policies and regulations, as they potentially influence the optimal system's configuration and operational strategy. In the case study of the university hospital, it is necessary to determine the conditions that allow the system to exchange electricity with the electric grid and install cogeneration devices.

The current regulatory framework for distributed generation in Brazil has been implemented by the Brazilian Electricity Regulatory Agency (ANEEL) through the Normative Resolution (NR) 482/2012 [69], updated in 2015 by the NR 687/2015 [70]. A detailed analysis of the policy context surrounding DG in Brazil can be found in Gucciardi Garcez [71] and in Dranka and Ferreira [72]. The NR 482/2012 establishes the general conditions for the access of DG to the net metering mechanism, known as Electrical Energy Compensation System (EECS). The Resolution defines DG as electricity production from any renewable source and/or qualified cogeneration connected to the distributed network through consumer unit facilities. DG is classified into microgeneration, with an installed capacity of up to $75 \mathrm{~kW}_{\mathrm{el}}$, and minigeneration, with an installed capacity between $75 \mathrm{~kW}_{\mathrm{el}}$ and $5 \mathrm{MW}_{\mathrm{el}}\left(3 \mathrm{MW}_{\mathrm{el}}\right.$ in the case of hydropower). Residential and tertiary sector (e.g. hospital, hotel, office, commercial center, school, university) consumers can install DG facilities and adhere to the net metering mechanism. 


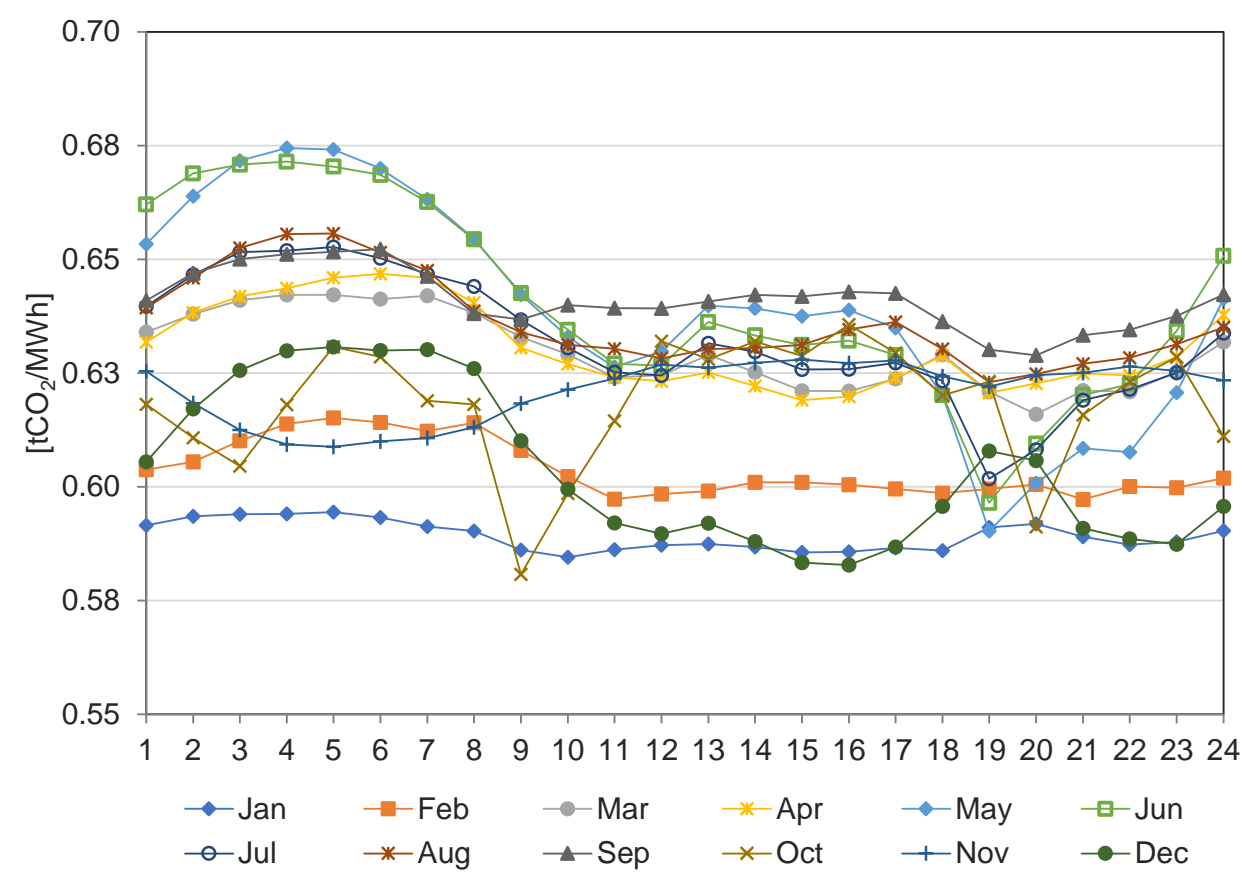

Figure 3: Hourly $\mathrm{CO}_{2}$ emission factors of the electricity in the national electric grid per month. Adapted from [68].

In the EECS, excess electricity production is injected into the distribution network, creating energy credits in $\mathrm{kWh}$, by means of a free loan. In this way, the grid works as a perfect (i.e. without losses) electric battery. When the system consumes electricity from the grid, existing energy credits are used to offset the consumption. The energy credits generated at a pricing period (e.g. on-peak) may be used to compensate electricity consumption at a different one (e.g. off-peak), in which case the ratio of the electricity tariff at the injection period to the electricity tariff at the consumption period is applied. At the end of a billing period, the remaining energy credits are carried over to the next. Any unused energy credits will expire 60 months after being created [70]. There is also the possibility of using energy credits to offset the consumption in other consumer units of the same ownership.

The requirements for the qualification of cogeneration facilities in Brazil have been established by the ANEEL NR 235/2006 [73]. The Resolution defines cogeneration as the process that takes place in a specific facility for the combined production of heat and mechanical energy (typically converted into electric energy) from a primary energy source. In addition, it is considered that the electromechanical utility is obtained between the resource and the heat recuperation. To be granted an operating license as "qualified cogeneration", the facility must fulfill two conditions, namely, a minimum equivalent electric efficiency and a minimum annual thermal efficiency. Both requirements involve assessing the total thermal energy supplied by the facility (i.e. without losses), the energy obtained from the resource in terms of the LHV, and the net electricity production. Additional factors are provided as a function of the installed capacity and type of resource consumed. The values considered for the present study, as well as the modelling of those constraints, are presented in detail in Section 2.4.3.1. 


\subsection{Renewable-based polygeneration system}

The following subsections introduce the renewable-based polygeneration system and present the main equipment data. The reader is referred to Pina et al. [55] for an in-depth description.

\subsubsection{Superstructure}

Figure 4 shows the superstructure of the polygeneration system. The energy resources available to the system include both renewable (solar radiation and biomass pellets) and conventional (natural gas and electricity purchased from the grid) types. The polygeneration system produces electricity, saturated steam at $180{ }^{\circ} \mathrm{C}$, hot water at $60^{\circ} \mathrm{C}$, and chilled water at $7^{\circ} \mathrm{C}$.

The candidate technologies can be divided into four categories: (i) generation technologies convert the energy resource into an intermediate or a final product; depending on the resource's availability, the generation technology may be classified as dispatchable (biomass hot water boiler $\mathrm{BH}$, biomass steam boiler $\mathrm{BV}$, natural gas hot water boiler $\mathrm{GH}$, natural gas steam boiler GV, and natural gas cogeneration module GE) or non-dispatchable or intermittent (photovoltaic panel PV, flat-plate solar thermal collector ST, parabolic trough concentrator PT); (ii) transformation technologies convert the energy resource or intermediate product into a final product (mechanical chiller EC, single-effect absorption chiller AS, and double-effect absorption chiller AD); (iii) storage technologies store the energy product for later use (hot water HS and chilled water CS storage tanks); and (iv) heat dissipation technology (cooling tower CT) dissipates to the ambient air the heat discarded by the transformation technologies and thermal integration subsystem.

The cogeneration module GE consists of an internal combustion engine (based on the Wärtsilä 34DF model series) coupled to a heat recovery system. The heat supplied by the generation technologies is directed to the thermal integration subsystem where it can be used to cover the steam and hot water demands as well as to drive the absorption chillers. In this context, a detailed characterization regarding the energy (quantity) and quality (temperature) levels of the thermal energy flows associated with the thermal energy technologies and services to be supplied to the building is necessary to ensure that thermodynamic principles are satisfied. The thermal integration subsystem has been modelled based on the transshipment model for heat integration by Papoulias and Grossmann [74] as explained in Pina et al. [55].

\subsubsection{Equipment data}

All candidate technologies included in the superstructure of Figure 4 are based on real, commercially available devices. The technical data correspond to a representative device of a series that was carefully selected to fit within the capacity range estimated based on the hospital's energy demands. The only exceptions are the solar RETs (PV, ST, and PT) due to their modular assembly, so their technical parameters are those of a specific model. The complete characterization of the devices is provided in Pina [56]. 


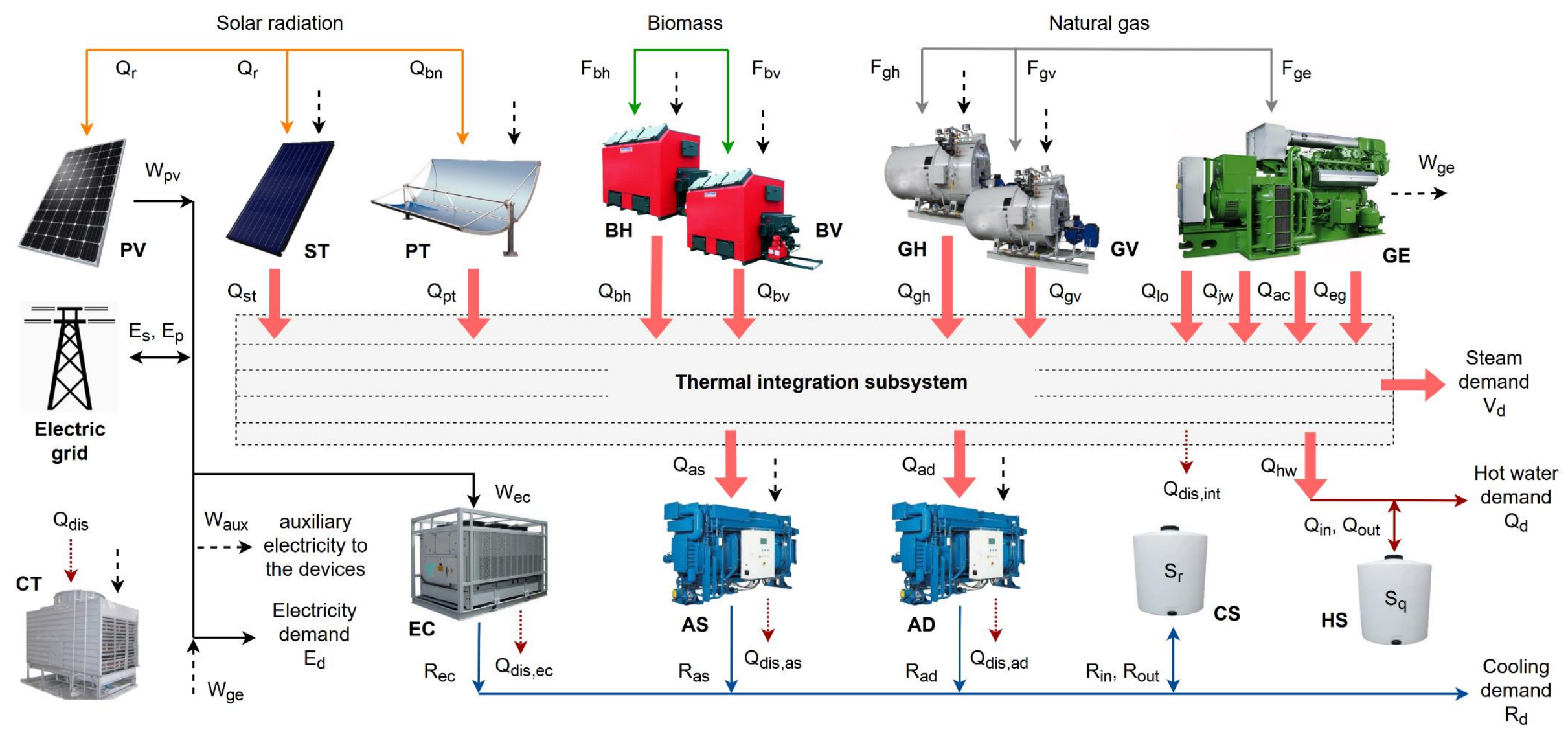

Figure 4: Superstructure of the renewable-based polygeneration system. 
Table 1 presents the technologies' main technical parameters, including the electric or thermal (LHV) efficiencies $\eta$, the coefficient of performance $C O P$, the unit auxiliary electricity consumption $C U e$, the area to power ratio Rap of solar-based RETs (in $\mathrm{m}^{2}$ of module surface area per $\mathrm{kW}$ installed), and the maximum installable capacity PIN MAX. Additional information about the PV, ST, and PT is provided in Table 2, Table 3, and Table 4, respectively.

Table 1: Candidate technologies' main technical data.

\begin{tabular}{|c|c|c|c|c|c|c|}
\hline & $\begin{array}{c}\text { Technology } \\
t\end{array}$ & $\begin{array}{c}\text { Efficiency } \\
\eta\end{array}$ & $\begin{array}{c}\text { Coefficient of } \\
\text { performance } \\
\text { COP }\end{array}$ & $\begin{array}{c}\text { Unit } \\
\text { electricity } \\
\text { consumption } \\
C U e, \\
\mathbf{k W}, / k W\end{array}$ & $\begin{array}{c}\text { Area to } \\
\text { power } \\
\text { ratio } \\
\text { Rap, } \\
\mathbf{m}^{2} / \mathrm{kW}\end{array}$ & $\begin{array}{c}\text { Maximum } \\
\text { installable } \\
\text { capacity } \\
\text { PINMAX, } \\
\text { kW }\end{array}$ \\
\hline PV & Photovoltaic panel & - & - & - & 5.7070 & 10,000 \\
\hline $\begin{array}{l}\text { ST } \\
\text { collecto }\end{array}$ & Flat-plate solar thermal & - & - & 0.0050 & 1.4286 & 5000 \\
\hline $\begin{array}{l}\text { PT } \\
\text { concent }\end{array}$ & $\begin{array}{l}\text { Parabolic trough } \\
\text { trator }\end{array}$ & - & - & 0.0164 & 1.5172 & 5000 \\
\hline GE & Cogeneration module & $0.467^{*}$ & - & 0.0300 & - & 5000 \\
\hline $\mathrm{BH}$ & Biomass hot water boiler & 0.850 & - & 0.0050 & - & 5000 \\
\hline BV & Biomass steam boiler & 0.850 & - & 0.0050 & - & 5000 \\
\hline GH & Natural gas hot water boiler & 0.920 & - & 0.0050 & - & 5000 \\
\hline GV & Natural gas steam boiler & 0.930 & - & 0.0050 & - & 5000 \\
\hline $\begin{array}{l}\text { AS } \\
\text { chiller }\end{array}$ & Single-effect absorption & - & 0.635 & 0.0050 & - & 5000 \\
\hline $\begin{array}{l}\mathrm{AD} \\
\text { chiller }\end{array}$ & Double-effect absorption & - & 1.410 & 0.0050 & - & 5000 \\
\hline EC & Mechanical chiller & - & 6.110 & - & - & 5000 \\
\hline $\mathrm{CT}$ & Cooling tower & 1.000 & - & 0.0050 & - & 10,000 \\
\hline HS & Hot water storage tank & 1.000 & - & - & - & $5000^{* *}$ \\
\hline CS & Chilled water storage tank & 1.000 & - & - & - & $5000^{* *}$ \\
\hline
\end{tabular}

*Electric efficiency; ${ }^{* *} \mathrm{kWh}$.

Table 2: Technical data - photovoltaic panel PV.

\begin{tabular}{lr}
\hline \multicolumn{1}{c}{ Parameter } & Value \\
\hline Manufacturer & Zytech \\
Model & $\mathrm{ZT} 340 \mathrm{P}$ \\
$P_{p v}:$ Maximum power & $0.34 \mathrm{kWp}$ \\
$A_{m, p v}:$ Module surface area & $1.94 \mathrm{~m}^{2}$ \\
$\eta_{p v}:$ Module efficiency & 0.1752 \\
$\mu_{T}:$ Temperature coefficient of power & $0.00388^{\circ} \mathrm{C}^{-1}$ \\
$T_{c, \text { NOCT: }}$ Cell temperature at NOCT conditions & $45^{\circ} \mathrm{C}$ \\
\hline
\end{tabular}


Table 3: Technical data - flat plate solar thermal collector ST.

\begin{tabular}{lr}
\hline \multicolumn{1}{c}{ Parameter } & Value \\
\hline Manufacturer & OkoTech \\
Model & Gluatmugl HT \\
$A_{m, s t}$ : Module surface area & $12 \mathrm{~m}^{2}$ \\
$\eta_{0}$ : Thermal coefficient & 0.806 \\
$k_{1}$ : Thermal coefficient & $2.580 \mathrm{~W} /\left(\mathrm{m}^{2} \cdot \mathrm{K}\right)$ \\
$k_{2}$ : Thermal coefficient & $0.009 \mathrm{~W} /\left(\mathrm{m}^{2} \cdot \mathrm{K}^{2}\right)$ \\
\hline
\end{tabular}

Table 4: Technical data - parabolic trough concentrator PT.

\begin{tabular}{lr}
\hline \multicolumn{2}{c}{ Parameter } \\
\hline Solar field \\
Total aperture area & $656 \mathrm{~m}^{2}$ \\
Direct normal irradiance at design point & $950 \mathrm{~W} / \mathrm{m}^{2}$ \\
Solar collector & \\
Model & SkyFuel SkyTrough \\
Orientation & North-South \\
Solar tracking & East-West \\
Tilt & $0^{\circ}$ \\
Solar Receiver & \\
Model & Schott PTR80 \\
Heat transfer fluid & Dowtherm RP \\
Inlet and outlet HTF temperature & $185-225^{\circ} \mathrm{C}$ \\
\hline
\end{tabular}

In each time interval, the maximum production of the technologies is limited, in general, to their installed capacities. For the solar RETs, however, their productions are also limited by local environmental conditions, such as solar irradiance (direct for the PT and global for the PV and ST) and ambient temperature, which vary hourly and daily. In the case of the PV and ST, it is assumed that they are fixed in place, facing north and with a tilt of $20^{\circ}$. Specific productions per $\mathrm{m}^{2}$ of PV and ST collector installed are calculated hour by hour throughout the year as follows.

For each hourly period $h$ of each representative day $d$, the unit electricity production in $\mathrm{kW} / \mathrm{m}^{2}$ of PV installed $x_{p v}(d, h)$ is determined by Eq. (1), according to the methodology described in Duffie et al. [75], with technical data $P_{p v}, A_{m, p v}, \mu_{T}, \eta_{p v}$ and $T_{c, N O C T}$ given in Table 2. Irradiance and cell temperature at SRC conditions are $Q_{r, S R C}=1 \mathrm{~kW} / \mathrm{m}^{2}$ and $T_{c, S R C}=25^{\circ} \mathrm{C}$, respectively. Irradiance and ambient temperature at NOCT conditions are $Q_{r, N O C T}=0.8$ $\mathrm{kW} / \mathrm{m}^{2}$ and $T_{a, N O C T}=20^{\circ} \mathrm{C}$, respectively. The efficiency of power-conditioning equipment $\eta_{e}$ $=0.9$. The hourly temperature correction factor $F_{t o p}(d, h)$ and the hourly cell temperature $T_{c, p v}(d, h)$ are obtained by solving Eqs. (2) and (3).

$x_{p v}(d, h)=\frac{P_{p v}}{A_{m, p v}} \cdot \frac{Q_{r}(d, h)}{Q_{r, S R C}} \cdot F_{t o p}(\mathrm{~d}, h) \cdot \eta_{e}$
$F_{t o p}(d, h)=1+\mu_{T} \cdot\left(T_{c, p v}(d, h)-T_{c, S R C}\right)$ 
$T_{c, p v}(d, h)=T_{a}(d, h)+\left(T_{c, N O C T}-T_{a, N O C T}\right) \cdot \frac{Q_{r}(d, h)}{Q_{r, N O C T}} \cdot\left(1-\frac{\eta_{p v} \cdot F_{t o p}(d, h)}{0.9}\right)$

For each hourly period $h$ of each representative day $d$, the unit heat production in $\mathrm{kW} / \mathrm{m}^{2}$ of ST installed $x_{s t}(d, h)$ is determined by Eq. (4), with technical data $\eta_{0}, k_{1}$ and $k_{2}$ given in Table 3. The ST working temperature $T_{s t}=90^{\circ} \mathrm{C}$ was considered.

$x_{s t}(d, h)=\operatorname{Max}\left(k_{0} \cdot Q_{r}(d, h)-k_{1} \cdot\left(T_{s t}-T_{a}(d, h)\right)-k_{2} \cdot\left(T_{s t}-T_{a}(d, h)\right)^{2} ; 0\right)$

Regarding the parabolic trough concentrator, the System Advisory Model (SAM) [76] was used to model and simulate the parabolic trough collector field. An in-depth explanation of the SAM model can be found in Wagner and Gilman [77]. The following SAM model's outputs have been given as input data to the optimization model developed herein: (i) the area to power ratio $\operatorname{Rap}(P T)$ of $1.5172 \mathrm{~m}^{2} / \mathrm{kW}$ (Table 1); and (ii) the unit heat production in $\mathrm{kW} / \mathrm{m}^{2}$ of PT installed $x_{p t}(d, h)$ for each hourly period $h$ of each representative day $d$. For more detail on the SAM model's results the reader is referred to Pina [56].

The economic costs and environmental impacts of installing the candidate technologies are given by the bare module cost $\mathrm{CI}$ and unit $\mathrm{CO}_{2}$ emissions $\mathrm{CO} 2 \mathrm{U}$, respectively, shown in Table 5. The $C I$ corresponds to the purchase cost multiplied by a simple module factor, which accounts for transportation, installation, connection costs, etc. Additional economic data include the amortization and maintenance factor fam $=0.15 \mathrm{yr}^{-1}$ and the indirect costs factor $f_{I C}=0.20$ [78]. The $C O 2 U$ corresponds to the $\mathrm{CO}_{2}$ emissions generated in the manufacturing process of the equipment. Also, it was considered that the plant's operational lifetime nyr $=$ 20 years.

Table 5: Bare module cost and unit $\mathrm{CO}_{2}$ emissions of the candidate technologies.

\begin{tabular}{|c|c|c|c|}
\hline & $\begin{array}{c}\text { Technology } \\
t\end{array}$ & $\begin{array}{c}\text { Bare module cost } C I \\
€ / \mathbf{k W}_{\text {nom }}\end{array}$ & $\begin{array}{c}\text { Unit } \mathrm{CO}_{2} \text { emissions } \mathrm{CO} U \\
\mathrm{~kg} \mathrm{CO}_{2} / \mathrm{kW}_{\mathrm{nom}}\end{array}$ \\
\hline $\mathrm{PV}$ & Photovoltaic panel & $1300[79]$ & $1840[80]$ \\
\hline ST & Flat-plate solar thermal collector & $500[81]$ & $140[81,82]$ \\
\hline PT & Parabolic trough concentrator & $425[83]$ & $130[84,85]$ \\
\hline GE & Cogeneration module & $675[78]$ & $65[86]$ \\
\hline BH & Biomass hot water boiler & 310 [87] & 15 [66] \\
\hline BV & Biomass steam boiler & 375 [87] & 20 [66] \\
\hline GH & Natural gas hot water boiler & $55[78]$ & 10 [86] \\
\hline GV & Natural gas steam boiler & $120[78]$ & 10 [86] \\
\hline AS & Single-effect absorption chiller & $260[78]$ & $165[86]$ \\
\hline $\mathrm{AD}$ & Double-effect absorption chiller & $260[78]$ & $165[86]$ \\
\hline EC & Mechanical chiller & $105[78]$ & $160[86]$ \\
\hline $\mathrm{CT}$ & Cooling tower & $30[78]$ & 25 [86] \\
\hline HS & Hot water storage tank & $40 € / \mathrm{kWh}[78]$ & $150 \mathrm{~kg} \mathrm{CO} 2 / \mathrm{kWh}[81]$ \\
\hline $\mathrm{CS}$ & Chilled water storage tank & $80 € / \mathrm{kWh}[78]$ & $300 \mathrm{~kg} \mathrm{CO} 2 / \mathrm{kWh}$ [81] \\
\hline
\end{tabular}




\subsection{Optimization procedure}

The optimization model was formulated as MILP to determine the optimal system configuration and multi-period operational planning of a renewable-based polygeneration system considering technical, economic, environmental, and regulatory aspects. The model is composed of decision variables representing (i) the technology's existence and size, and, for each time interval, (ii) the energy flows consumed/produced by each technology, (iii) the purchased and/or sold energy resources, (iv) the energy stored in the TES units, (v) energy balances, and (vi) thermal integration between hot and cold flows supplied and required by technologies and the consumer center. Binary variables are used to introduce structural (permission to install technologies) and operational (permission to sell electricity to the grid) restrictions, while all other variables are continuous. For the multi-period operation, the model takes into account the variability of climatic conditions, energy resources, and energy demands, as well as changes in energy resources prices and grid $\mathrm{CO}_{2}$ emissions. Local regulations concerning the installation of cogeneration units and the interconnection with the electric grid are also considered.

\subsubsection{Objective functions}

The economic objective function is the total annual cost $C T E_{t o t}$, expressed by Eq. (5), composed of a fixed term, relative to the annual fixed cost $C T E_{f i x}$, and a variable term, relative to the annual variable cost $C T E_{\text {var }}$.

Min $C T E_{t o t}=C T E_{f i x}+C T E_{\text {var }}$

The annual fixed cost $C T E_{f i x}$ is expressed by Eq. (6) in which $P I N(t)$ is the installed capacity of technology $t$.

$$
C T E_{f i x}=f a m \cdot\left(1+f_{I C}\right) \cdot \sum_{t} C I(t) \cdot \operatorname{PIN}(t)
$$

The annual variable cost $C T E_{v a r}$ is calculated as the sum of the purchasing costs of natural gas $C T E_{\text {gas }}$, biomass $C T E_{\text {bio }}$ and electricity $C T E_{\text {ele }}$ for each time interval throughout the year.

$$
\begin{aligned}
& C T E_{\text {var }}=\sum_{d, h} N R Y(d) \cdot\left(\operatorname{CTE}_{\text {gas }}(d, h)+C T E_{\text {bio }}(d, h)+\operatorname{CTE}_{\text {ele }}(d, h)\right) \\
& \operatorname{CTE} E_{\text {gas }}(d, h)=p_{\text {gas }} \cdot\left(F_{g h}(d, h)+F_{g v}(d, h)+F_{g e}(d, h)\right) \\
& C T E_{\text {bio }}(d, h)=p_{\text {bio }} \cdot\left(F_{b h}(d, h)+F_{b v}(d, h)\right) \\
& C T E_{\text {ele }}(d, h)=p_{e p}(d, h) \cdot E_{p}(d, h)-p_{e s}(d, h) \cdot E_{s}(d, h)
\end{aligned}
$$

Analogous to the economic criterion, the environmental objective function is the total annual $\mathrm{CO}_{2}$ emissions $\mathrm{CO} 2_{\text {tot }}$, expressed by Eq. (11), composed of the annual fixed emissions $\mathrm{CO} 2_{f i x}$ (Eq. (12)) and the annual variable emissions $\mathrm{CO}_{\text {var }}$ (Eq. (13)).

$\operatorname{Min} C O 2_{\text {tot }}=C O 2_{f i x}+C O 2_{v a r}$ 


$$
\begin{aligned}
& C O 2_{f i x}=\sum_{t} \operatorname{CO2U}(t) \cdot \operatorname{PIN}(t) / n y r \\
& C O 2_{\text {var }}=\sum_{d, h} N R Y(d) \cdot\left(\operatorname{CO2}_{\text {gas }}(d, h)+C O 2_{\text {bio }}(d, h)+C O 2_{\text {ele }}(d, h)\right) \\
& C O 2_{\text {gas }}(d, h)=k g C O 2_{\text {gas }} \cdot\left(F_{g h}(d, h)+F_{g v}(d, h)+F_{g e}(d, h)\right) \\
& C O 2_{\text {bio }}(d, h)=k g C O 2_{\text {bio }} \cdot\left(F_{b h}(d, h)+F_{b v}(d, h)\right) \\
& C O 2_{\text {ele }}(d, h)=k g C O 2_{\text {ele }}(d, h) \cdot\left(E_{p}(d, h)-E_{s}(d, h)\right)
\end{aligned}
$$

\subsubsection{System constraints}

The objective functions are subject to equipment (capacity limits and production restrictions), energy balances, electric grid, local policies, and thermal integration constraints, which have been thoroughly described in Pina et al. [55]. In this section, we will focus on the constraints most relevant to the renewable energy technologies, TES units, and local regulations.

\subsubsection{Installed capacity limits}

For each candidate technology $t$, the installed capacity $\operatorname{PIN}(t)$ must be lower than or equal to the maximum installable capacity $P I N_{M A X}(t)$, as expressed by Eq. (17), where $y I N S(t)$ is a binary variable that expresses the permission to install or not the technology $t$.

$P I N(t) \leq y I N S(t) \cdot P I_{M A X}(t)$

\subsubsection{Production restrictions}

\section{Dispatchable generation technologies and transformation technologies}

An example is given for the biomass hot water boiler BH. The production of the technology is limited to its installed capacity by the inequality constraint of Eq. (18). The fuel consumption is related to the energy production by the equality constraint of Eq. (19). Also, the auxiliary electricity consumption is calculated according to Eq. (20).

$Q_{b h}(d, h) \leq P I N(B H)$

$Q_{b h}(d, h)-\eta_{b h} \cdot F_{b h}(d, h)=0$

$W_{a u x, b h}(d, h)=C U e(B H) \cdot Q_{b h}(d, h)$

\section{Solar RETs}

The PV, ST, and PT productions depend on the corresponding hourly unit production per $\mathrm{m}^{2}$ of module installed, area to power ratio, and installed capacity, as expressed by Eqs. (21)(23), respectively. The auxiliary electricity consumption of the ST and PT are determined in the same way as explained for Eq. (20).

$$
\begin{aligned}
& Q_{p v}(d, h) \leq x_{p v}(d, h) \cdot \operatorname{Rap}(P V) \cdot \operatorname{PIN}(P V) \\
& Q_{s t}(d, h) \leq x_{s t}(d, h) \cdot \operatorname{Rap}(S T) \cdot \operatorname{PIN}(S T) \\
& Q_{p t}(d, h) \leq x_{p t}(d, h) \cdot \operatorname{Rap}(P T) \cdot \operatorname{PIN}(P T)
\end{aligned}
$$




\section{Thermal energy storage units}

In the case of the TES, for instance the hot water storage tank HS, the energy stored at the end of any hourly period $S_{q}(d, h)$, in $\mathrm{kWh}$, is limited to the installed capacity $\operatorname{PIN}(H S)$, according to Eq. (24). The energy balance in the HS is given by Eq. (25), in which the charged $Q_{i n}(d, h)$ and discharged $Q_{\text {out }}(d, h)$ energy flows, in $\mathrm{kW}$, are multiplied by the duration of the period $N H P(h)=1$ hour in order to convert them to the same unit as the stored energy in $\mathrm{kWh}$.

$S_{q}(d, h) \leq P I N(H S)$

$S_{q}(d, h-1)+\left(Q_{\text {in }}(d, h)-Q_{\text {out }}(d, h)\right) \cdot N H P(h)-S_{q}(d, h)=0$

It should be noted that, for the present analysis, there are no energy losses in the TES units. Considering the daily cyclical characteristic of the system operation, by the end of the day the TES returns to its initial state, so that the energy stored at the end of the day must be equal to the energy stored at the beginning of that day.

\subsubsection{General electric grid constraints}

The binary variables $y E p$ and $y E s$ express the permission for purchase and sale of electricity, respectively. Their applications are shown in Eqs. (26) and (27) in relation to the purchased $E_{p}(d, h)$ and sold $E_{s}(d, h)$ electricity, respectively.

$E_{p}(d, h) \leq y E p \cdot\left(E_{d}(d, h)+W_{e c}(d, h)+W_{a u x}(d, h)\right)$

$E_{s}(d, h) \leq y E s \cdot\left(W_{p v}(d, h)+W_{g e}(d, h)\right)$

\subsubsection{Local regulations constraints}

\subsubsection{Qualified cogeneration constraints}

As explained in Section 2.2.4, the qualification of cogeneration facilities in Brazil requires fulfilling a minimum annual equivalent electric efficiency $E E E_{-} Y$, expressed by Eq. (28), and a minimum annual heat efficiency $\eta_{q_{-}} Y$, expressed by Eq. (29). The annual heat efficiency considers the useful cogenerated heat, that is, the difference between the cogenerated heat produced $Q_{g e_{-} Y}$ and wasted $Q_{d i s, i n t} Y$, whose calculation in the thermal integration subsystem (Figure 4) has been explained in detail in [55]. The annual electric efficiency $\eta_{w, Y}$ is given by Eq. (30). The numerical parameters $(2.14,41 \%$, and $15 \%)$ are provided by the regulation NR 235/2006 according to the cogeneration capacity and fuel consumed [73]. The subscript_Y denotes annual values.

$$
\begin{aligned}
& E E E_{-} Y=\eta_{w_{-} Y}+\eta_{q_{-} Y} / 2.14 \geq 0.41 \\
& \eta_{q_{-} Y}=\left(Q_{g e_{-} Y}-Q_{d i s, i n t_{-} Y}\right) / F_{g e_{-} Y}>0.15 \\
& \eta_{w_{-} Y}=W_{g e_{-} Y} / F_{g e_{-} Y}
\end{aligned}
$$




\subsubsection{Electrical energy compensation system modelling}

This section modifies the optimization model described thus far by implementing the condition for the access to the EECS described in Section 2.2.4. This implementation will be used exclusively in the modality D (Brazilian case) described in Section 3.

The permission to purchase electricity from the grid remains active (i.e. $y E p=1$ ). On the other hand, selling electricity to the grid is no longer possible (i.e. $y E s=0$ ), since now the power exchange with the grid is accounted in terms of energy credits. The binary variable $y E E C S=1$ has been introduced to represent the access to the EECS.

In each time interval, the power exchange with the grid is represented by purchased electricity $E_{p}(d, h)$, imported electricity $E_{\text {imp }}(d, h)$, and exported electricity $E_{\text {exp }}(d, h)$. The electricity balance in the system is thus expressed as

$E_{p}(d, h)+E_{i m p}(d, h)+W_{p v}(d, h)+W_{g e}(d, h)-E_{d}(d, h)-W_{e c}(d, h)-W_{a u x}(d, h)-E_{\text {exp }}(d, h)=0$

The $E_{\text {exp }}(d, h), E_{\text {imp }}(d, h)$, and $E_{p}(d, h)$ are limited according to Eqs. (32)-(34). Two additional binary variables $y I E(d, h)$ and $y E E(d, h)$ were introduced to prevent the system from simultaneously importing and exporting electricity.

$$
\begin{aligned}
& E_{\text {exp }}(d, h) \leq y E E C S \cdot\left(W_{p v}(d, h)+W_{g e}(d, h)\right) \\
& E_{\text {imp }}(d, h) \leq y E E C S \cdot\left(E_{d}(d, h)+W_{e c}(d, h)+W_{a u x}(d, h)\right) \\
& E_{p}(d, h) \leq y E p \cdot\left(E_{d}(d, h)+W_{e c}(d, h)+W_{a u x}(d, h)-E_{\text {imp }}(d, h)\right)
\end{aligned}
$$

The EECS can be represented in economic terms by computing the cost of the net electricity consumed by the system in the month; if the system exports more electricity than it consumes, the revenue is carried over to the next month, up to 60 months. In order to maintain an annual cyclic behavior to the system operation, it is considered herein the revenue remains valid for only 12 months, after which any remaining revenue is lost. Therefore, the following constraint is introduced for the annual balance of imported $E_{i m p}(d, h)$ and exported $E_{\exp }(d, h)$ electricity:

$\sum_{d, h} N R Y(d) \cdot p_{e p}(d, h) \cdot\left(E_{\text {imp }}(d, h)-E_{\text {exp }}(d, h)\right) \leq 0$

Regarding the objective functions, the electricity cost $C T E_{\text {ele }}(d, h)$ defined by Eq. (10) corresponds now only to the purchase cost, as expressed by Eq. (36). In the case of the environmental objective function, the $C O 2_{\text {ele }}(d, h)$ defined by Eq. (16) can be rewritten as Eq. (37), which accounts for the $\mathrm{CO}_{2}$ emissions associated with the electricity purchased, imported, and exported.

$$
\begin{aligned}
& C T E_{\text {ele }}(d, h)=p_{\text {ep }}(d, h) \cdot E_{p}(d, h) \\
& C O 2_{\text {ele }}(d, h)=k g C O 2_{\text {ele }}(d, h) \cdot\left(E_{p}(d, h)+E_{\text {imp }}(d, h)-E_{\text {exp }}(d, h)\right)
\end{aligned}
$$




\section{Results}

The mathematical model was implemented and solved using the software LINGO [88]. As previously explained, binary variables are used in the optimization model to impose structural (regarding the permission to install technologies) and operational (regarding the permission to purchase/sell electricity) restrictions. For the optimal economic cost and environmental solutions analyzed herein, all candidate technologies in the superstructure depicted in Figure 4 were allowed to be installed ( $y I N S(t)=1$, for all technologies $t$ ). Moreover, four modalities of power exchange with the grid were proposed, as described by the binary variables and logical restrictions shown in Table 6.

Table 6: Modalities of power exchange with the grid.

\begin{tabular}{cl}
\hline Modality & Only purchase is allowed \\
\hline A - Purchase only & $y E p=1 ; y E s=0$ \\
& Purchase and sale are allowed with the condition of purchasing more \\
& electricity than it sells annually \\
& $y E p=1 ; y E s=1$ \\
B - Annual consumer & $E p_{-} Y-E s_{-} Y>=0$ \\
& Purchase and sale are allowed with no restraints. \\
& $y E p=1 ; y E s=1$ \\
C - Unrestricted sale & See Section 2.4 .3 .2 \\
&
\end{tabular}

Modalities A, B and C correspond to general cases in which the permission to sell electricity to the grid is gradually relaxed from not allowed (modality A) to allowed with an upper limit (modality B) to allowed with no restraints (modality C). Modality D corresponds to the particular case of the Brazilian net metering regulations in which electricity is no longer sold to the grid, but rather exported as free loan compensating the electricity purchase in later time intervals, as explained in Section 2.2.4 and modelled in Section 2.4.3.2. Therefore, modality $\mathrm{D}$ is not an extension of modalities $\mathrm{A}, \mathrm{B}$ and $\mathrm{C}$.

A reference system was defined to provide a basis for comparison. In this system only the gas boilers $\mathrm{GH}$ and $\mathrm{GV}$, mechanical chiller $\mathrm{EC}$, and the cooling tower $\mathrm{CT}$ were allowed to be installed $(y I N S(t)=1$, for $t=\mathrm{GH}, \mathrm{GV}, \mathrm{EC}$, and CT; $y I N S(t)=0$, for the other technologies), and the system is only allowed to purchase electricity from the grid $(y E p=1 ; y E s=0)$.

\subsection{Economic cost optimal solutions}

The system configurations and the main results obtained for the optimal economic cost solutions are shown in Table 7 and Table 8.

In the reference system, the electricity demand and the electricity internally consumed by the system were supplied by the electric grid. The hot water and steam demands were predominantly covered by the natural gas steam boiler GV, supported by the natural gas hot water boiler $\mathrm{GH}$, and cooling was produced in the mechanical chiller EC with electricity purchased from the grid. The cooling tower CT was installed to dissipate heat from the EC. 
The total annual cost was $1,256,245 € / y r$, of which $96.8 \%$ corresponded to variable (operation) costs and the remaining $3.2 \%$ corresponded to fixed (installation) costs.

The optimal cost solutions under modalities A through $\mathrm{C}$ included the same set of technologies, namely GE, GV, AS, EC, and CT, although their installed capacities varied in each case. Even though the TES units were also included, their capacities were almost negligible. The cogeneration module GE operated with very high load factors, covering most of the electricity and heat consumed by the systems. The single-effect absorption chiller AS was the main device for cooling production (mainly driven by cogenerated heat) and operated with very high load factors similarly to those of the GE. In addition to the electric grid, the GV and EC were installed as auxiliary devices to support the GE and AS. In contrast to the reference system, the optimal cost polygeneration systems were much more reliant on natural gas than on electricity purchase.

Relaxing the conditions for electricity exchange with the grid (from modality A to B to C) promoted the deployment of GE, AS and CT, and reduced the GV and EC. As a result, larger shares of the electricity, heat and cooling demands were covered with cogenerated products, and the system was able to sell more electricity to the grid. Electricity sale had a twofold effect on the economic and environmental objective functions. On the one hand, it generated revenue to partially compensate the total annual cost, and on the other hand, it displaced grid $\mathrm{CO}_{2}$ emissions, thereby reducing the total annual $\mathrm{CO}_{2}$ emissions of the system.

In the case of the Brazilian EECS (modality D) similar results were obtained. It is worth stressing that under the EECS the system no longer sells electricity to the grid generating revenue, but rather exports it as free loan to compensate consumption later; the exported electricity that is not consumed after the period of one year is lost. From the economic perspective, this means that exporting electricity is only interesting as long as it can be consumed back later. Therefore, there is a balance between the amount of electricity to be exported and the amount of electricity that the system is able to consume. For this reason, the installed capacity of GE was not as high as that of modality C (unrestricted sale).

Compared to the optimal cost solution under modality A (purchase only), the same set of technologies was installed, with higher load factors of the GE and AS. It was observed that all exported electricity was imported back, so that no electricity purchase was required. The reason that the values of exported and imported electricity were slightly different in Table 8 was that the annual balance of Eq. (35) is made in economic terms applying the electricity purchase price at the corresponding time interval (on-peak or off-peak), as explained in Section 2.4.3.2. 
Table 7: Economic cost optimization - Reference system and optimal cost polygeneration systems layouts.

\begin{tabular}{|c|c|c|c|c|c|c|c|c|c|c|c|c|c|c|c|}
\hline \multirow{2}{*}{$\begin{array}{c}\text { Technology } \\
t\end{array}$} & \multicolumn{3}{|c|}{ Reference system } & \multicolumn{3}{|c|}{ A - Purchase only } & \multicolumn{3}{|c|}{ B - Annual consumer } & \multicolumn{3}{|c|}{ C - Unrestricted sale } & \multicolumn{3}{|c|}{ D - EECS } \\
\hline & $\begin{array}{c}P I N, \\
\mathrm{~kW}\end{array}$ & $\begin{array}{c}f u, \\
\%\end{array}$ & $\begin{array}{l}Z, \\
\mathbf{k} €\end{array}$ & $\begin{array}{l}P I N, \\
\text { kW }\end{array}$ & $\begin{array}{c}f u, \\
\%\end{array}$ & $\begin{array}{l}Z, \\
\mathbf{k} €\end{array}$ & $\begin{array}{c}P I N, \\
\mathbf{k W}\end{array}$ & $\begin{array}{c}f u, \\
\%\end{array}$ & $\begin{array}{l}Z, \\
\mathbf{~} €\end{array}$ & $\begin{array}{l}P I N, \\
\text { kW }\end{array}$ & $\begin{array}{c}f u, \\
\%\end{array}$ & $\begin{array}{l}Z, \\
\mathbf{k} €\end{array}$ & $\begin{array}{l}P I N, \\
\mathbf{k W}\end{array}$ & $\begin{array}{c}f u, \\
\%\end{array}$ & $\begin{array}{l}Z, \\
\mathbf{k} €\end{array}$ \\
\hline GE & - & - & - & 1,157 & 91.28 & 781.3 & 1,190 & 98.65 & 803.5 & 1,591 & 99.89 & $1,073.9$ & 1,206 & 97.25 & 813.7 \\
\hline PV & - & - & - & 0 & - & - & 0 & - & - & 0 & - & - & 0 & - & - \\
\hline PT & - & - & - & 0 & - & - & 0 & - & - & 0 & - & - & 0 & - & - \\
\hline $\mathrm{ST}$ & - & - & - & 0 & - & - & 0 & - & - & 0 & - & - & 0 & - & - \\
\hline $\mathrm{GH}$ & 76 & 1.56 & 4.2 & 0 & - & - & 0 & - & - & 0 & - & - & 0 & - & - \\
\hline $\mathrm{GV}$ & 780 & 75.61 & 93.6 & 314 & 38.85 & 37.7 & 301 & 25.97 & 36.1 & 139 & 6.50 & 16.7 & 295 & 25.12 & 35.3 \\
\hline $\mathrm{BH}$ & - & - & - & 0 & - & - & 0 & - & - & 0 & - & - & 0 & - & - \\
\hline $\mathrm{BV}$ & - & - & - & 0 & - & - & 0 & - & - & 0 & - & - & 0 & - & - \\
\hline $\mathrm{EC}$ & 879 & 61.75 & 92.3 & 505 & 44.70 & 53.1 & 495 & 38.62 & 52.0 & 345 & 23.17 & 36.2 & 503 & 36.94 & 52.8 \\
\hline AS & - & - & - & 350 & 90.50 & 91.1 & 364 & 96.73 & 94.5 & 489 & 90.49 & 127.2 & 368 & 97.04 & 95.7 \\
\hline $\mathrm{AD}$ & - & - & - & 0 & - & - & 0 & - & - & 38 & 54.21 & 9.8 & 0 & - & - \\
\hline CT & 1,023 & 61.75 & 30.7 & 1,492 & 75.22 & 44.7 & 1,514 & 78.28 & 45.4 & 1,753 & 85.31 & 52.6 & 1,535 & 76.79 & 46.0 \\
\hline $\mathrm{HS}, \mathrm{kWh}$ & - & - & - & 12 & - & 0.5 & 9 & - & 0.4 & 0 & - & - & 4 & - & 0.2 \\
\hline $\mathrm{CS}, \mathrm{kWh}$ & - & - & - & 39 & - & 3.1 & 33 & - & 2.6 & 31 & - & 2.5 & 8 & - & 0.7 \\
\hline Investment cost, $\mathrm{k} €$ & & & 220.8 & & & $1,011.4$ & & & $1,034.5$ & & & $1,318.8$ & & & $1,044.4$ \\
\hline
\end{tabular}


Table 8: Economic cost optimization - Main results for the reference system and optimal cost polygeneration systems.

\begin{tabular}{|c|c|c|c|c|c|}
\hline Results & Reference system & A - Purchase only & B - Annual consumer & C-Unrestricted sale & D-EECS \\
\hline Natural gas, MWh/yr & $5,567,170$ & $20,947,483$ & $22,741,059$ & $29,865,601$ & $22,666,329$ \\
\hline Biomass, MWh/yr & - & 0 & 0 & 0 & 0 \\
\hline Purchased electricity, MWh/yr & $10,465,556$ & $1,048,062$ & 928,268 & 98,261 & 0 \\
\hline Sold electricity, MWh/yr & - & - & 928,268 & $3,767,648$ & - \\
\hline Imported electricity, MWh/yr & - & - & - & - & $1,041,609$ \\
\hline Exported electricity, MWh/yr & - & - & - & - & $1,033,145$ \\
\hline Natural gas, $\mathrm{kg} \mathrm{CO}_{2} / \mathrm{yr}$ & $1,124,568$ & $4,231,392$ & $4,593,694$ & $6,032,851$ & $4,578,598$ \\
\hline Biomass, $\mathrm{kg} \mathrm{CO}_{2} / \mathrm{yr}$ & - & 0 & 0 & 0 & 0 \\
\hline Purchased electricity, $\mathrm{kg} \mathrm{CO}_{2} / \mathrm{yr}$ & $6,508,147$ & 644,615 & 570,826 & 59,493 & 0 \\
\hline Sold electricity, $\mathrm{kg} \mathrm{CO}_{2} / \mathrm{yr}$ & - & - & $-590,561$ & $-2,368,923$ & 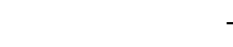 \\
\hline Imported electricity, $\mathrm{kg} \mathrm{CO}_{2} / \mathrm{yr}$ & - & - & - & - & 642,795 \\
\hline Exported electricity, $\mathrm{kg} \mathrm{CO}_{2} / \mathrm{yr}$ & - & - & - & - & $-656,576$ \\
\hline Annual variable $\mathrm{CO}_{2}$ emissions, $\mathrm{kg} \mathrm{CO}_{2} / \mathrm{yr}$ & $7,632,715$ & $4,876,006$ & $4,573,959$ & $3,723,422$ & $4,564,818$ \\
\hline Annual fixed $\mathrm{CO}_{2}$ emissions, $\mathrm{kg} \mathrm{CO}_{2} / \mathrm{yr}$ & 8,741 & 13,391 & 13,436 & 15,001 & 13,197 \\
\hline Total annual $\mathrm{CO}_{2}$ emissions, $\mathrm{kg} \mathrm{CO}_{2} / \mathrm{yr}$ & $7,641,456$ & $4,889,397$ & $4,587,395$ & $3,738,423$ & $4,578,015$ \\
\hline Natural gas, $€ / \mathrm{yr}$ & 194,851 & 733,162 & 795,937 & $1,045,296$ & 793,322 \\
\hline Biomass, $€ / y r$ & - & 0 & 0 & 0 & 0 \\
\hline Purchased electricity, $€ / \mathrm{yr}$ & $1,021,641$ & 100,140 & 88,466 & 9,236 & 0 \\
\hline Sold electricity, $€ / \mathrm{yr}$ & - & - & $-77,680$ & $-322,072$ & - \\
\hline Annual variable cost, $€ / \mathrm{yr}$ & $1,216,492$ & 833,302 & 806,723 & 732,461 & 793,322 \\
\hline Annual fixed cost, $€ / \mathrm{yr}$ & 39,753 & 182,058 & 186,210 & 237,392 & 188,000 \\
\hline Total annual cost, $€ / \mathrm{yr}$ & $1,256,245$ & $1,015,360$ & 992,933 & 969,853 & 981,322 \\
\hline GE annual heat efficiency & - & $42.8 \%$ & $42.5 \%$ & $38.1 \%$ & $43.0 \%$ \\
\hline
\end{tabular}


Regarding the economic and environmental viewpoints, a comparison of the optimal cost polygeneration systems relative to the reference system is made in Table 9. The polygeneration systems under each modality had lower total annual costs than the reference system. While the polygeneration systems' more complex configurations required higher investment costs, their more efficient operation reduced the annual variable costs, resulting in positive total annual cost savings. In addition, the revenue generated from selling electricity to the grid under modalities B and C, as well as the electricity cost abatement under modality D, contributed to further reducing the annual variable costs. The greatest savings were achieved under modality $\mathrm{C}$. The simple payback periods (annual variable cost savings divided by the additional investment cost) of the optimal cost solutions under each modality were about the same, the lowest (1.9 years) corresponding to modality D and the highest (2.3 years) corresponding to modality $\mathrm{C}$. From the environmental perspective, it is interesting to note that the optimal cost polygeneration systems emitted less $\mathrm{CO}_{2}$ emissions than the reference system, even without installing any RETs. Annual $\mathrm{CO}_{2}$ emissions savings were especially higher when the system was allowed to inject electricity into the grid, reaching a reduction of $51.1 \%$ under modality $\mathrm{C}$.

Table 9: Optimal economic cost polygeneration systems relative to the reference system.

\begin{tabular}{lrrrr}
\hline \multicolumn{1}{c}{ Result } & $\begin{array}{c}\text { A - Purchase } \\
\text { only }\end{array}$ & $\begin{array}{c}\text { B - Annual } \\
\text { consumer }\end{array}$ & $\begin{array}{r}\text { C - Unrestricted } \\
\text { sale }\end{array}$ & D - EECS \\
\hline Additional investment cost, $\mathrm{k} €$ & 790.6 & 813.7 & $1,098.0$ & 823.6 \\
Annual variable cost savings, $\mathrm{k} € / \mathrm{yr}$ & 383.2 & 409.8 & 484.0 & 423.2 \\
Payback period, yr & 2.1 & 2.0 & 2.3 & 1.9 \\
Annual $\mathrm{CO}_{2}$ emissions savings, $\mathrm{tCO}_{2} / \mathrm{yr}$ & $2,752.1$ & $3,054.1$ & $3,903.0$ & $3,063.4$ \\
Annual $\mathrm{CO}_{2}$ emissions savings, $\%$ & $36.0 \%$ & $40.0 \%$ & $51.1 \%$ & $40.1 \%$ \\
\hline
\end{tabular}

As can be seen, the GE was proved economically feasible under all modalities of power exchange with the grid, resulting in installed capacities between 1.1 and 1.6 MW and very high load factors. Relative to the reference system, the presence of the GE: (i) eliminated the $\mathrm{GH}$; (ii) reduced the installed capacities of GV and EC by 40-60\%; and (iii) enabled the installation of the AS. Similar results were obtained in a previous paper by the authors [55]; however, in that work TES units and RETs had not been considered.

In addition, it became clear that the GE was economically interesting either with or without the permission to sell electricity to the grid. In fact, it was observed that the more leeway the system was given to sell electricity (moving from modality A to B to C), the higher the installed capacity and load factor of the GE. Also, a positive synergy was observed between the GE and the AS, which indicated the economic feasibility of producing cooling with cogenerated heat. However, the fact that none of the RETs were included in the optimal cost solutions called for an in-depth analysis of the parameters used in the optimization model, as described in the following section.

\subsection{Incorporation of renewable energy technologies under the Brazilian EECS}

This section analyzes the conditions that would enable the incorporation of renewable energy technologies in the optimal economic cost polygeneration system. Since the EECS is the net 
metering scheme currently in force in Brazil, modality D is considered herein. The performed analyses include: (i) sensitivity analysis of the energy resources purchase prices; (ii) sensitivity analysis of the investment costs of solar RETs; and (iii) the consideration of a total ban on fossil fuel consumption. It should be noted that variations in energy resources prices and investment costs may be due to many reasons, such as economic, environmental, technological, and legal. For this reason, the sensitivity analyses performed in this section provide insight about the possible effect of implementing subsidies, surcharges, tax exemptions, etc.

\subsubsection{Sensitivity to purchase prices of energy resources}

The purchase price of natural gas $p_{\text {gas }}$ considered in the economic analysis was equal to 0.035 $€ / \mathrm{kWh}(\mathrm{LHV})$. This value was varied between 0.020 and $0.055 € / \mathrm{kWh}(\mathrm{LHV})$. Figure 5 (a) shows the total annual cost (objective function) and total annual $\mathrm{CO}_{2}$ emissions of the optimal cost solution, and Figure 5 (b) presents the installed capacities of selected equipment, namely the cogeneration module GE, single-effect absorption chiller AS, mechanical chiller EC, and biomass steam boiler BV.

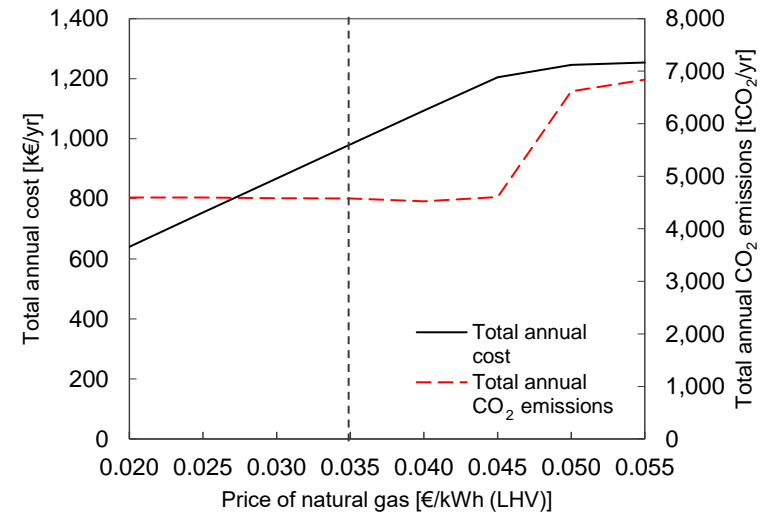

(a)

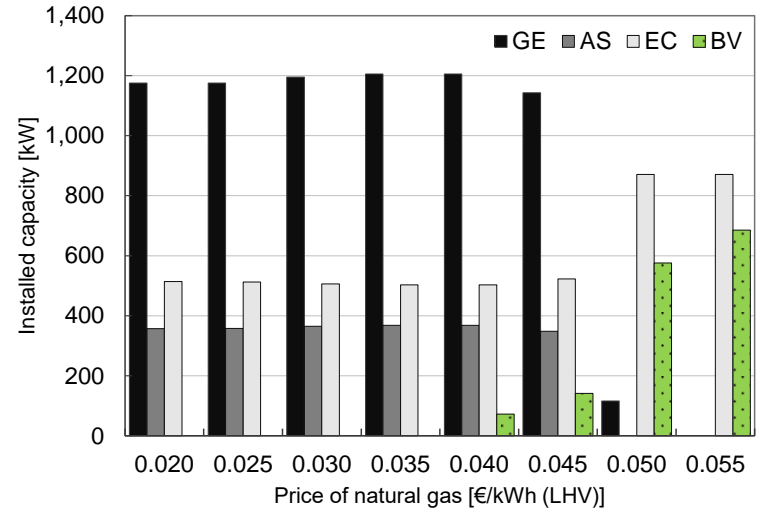

(b)

Figure 5: Sensitivity analysis of the price of natural gas: (a) total annual cost (objective function) and total annual $\mathrm{CO}_{2}$ emissions, and (b) installed capacities of selected equipment.

As previously mentioned, the EECS implies a balance between exported and imported electricity, as the system no longer sells electricity to the grid generating revenue, but rater exports it as free loan to compensate electricity purchase later. For lower values of $p_{\text {gas }}$, the system configuration and operation remained virtually unchanged, with the same total annual $\mathrm{CO}_{2}$ emissions, while the total annual costs decreased along with the $p_{\text {gas }}$. The reason is because for $p_{\text {gas }}=0.035 € / \mathrm{kWh}$ (LHV) the system already exported as much electricity as it imported (i.e. electricity purchase was zero), so there was no point in increasing the installed capacity of GE, since any additional exported electricity would be lost. By contrast, increasing $p_{\text {gas }}$ by only $14 \%$ was enough to promote the installation of the $\mathrm{BV}$, which slightly displaced the GV. For greater values of $p_{\text {gas }}$, more BV was installed, displacing both the GV and GE. The synergy between the GE and AS was clearly observed here, as their installed capacities followed similar trends. As the AS decreased, it was replaced by the EC. It is interesting to note that the phasing out of cogeneration for $p_{\text {gas }}$ values over $0.045 € / \mathrm{kWh}$ 
(LHV) resulted in a drastic increase in the total annual $\mathrm{CO}_{2}$ emissions. This is explained by the fact that when the system exports electricity to the grid, it displaces the $\mathrm{CO}_{2}$ emissions associated with the grid electricity at that time. Therefore, by curtailing cogeneration, the total annual $\mathrm{CO}_{2}$ emissions of the system go up.

The sensitivity analysis of the purchase price of biomass $p_{b i o}$ was carried out by varying the current price of 0.026 down to $0.005 € / \mathrm{kWh}$ (LHV). It made no sense to increase it, since biomass boilers were not included in the optimal economic cost solution. Figure 6 (a) shows the total annual cost (objective function) and total annual $\mathrm{CO}_{2}$ emissions of the optimal cost solution, and Figure 6 (b) presents the installed capacities of selected equipment, namely the cogeneration module GE, double-effect absorption chiller $\mathrm{AD}$, natural gas steam boiler GV, and biomass steam boiler BV. The results show that reducing the $p_{\text {bio }}$ promoted the installation of $\mathrm{BV}$, which partially displaced the GV and only marginally displaced the GE. The impact on the total annual cost and total annual $\mathrm{CO}_{2}$ emissions, however, was negligible. It is noteworthy that for very cheap biomass prices it could become economically interesting to produce cooling in the $\mathrm{AD}$ with steam from the $\mathrm{BV}$.

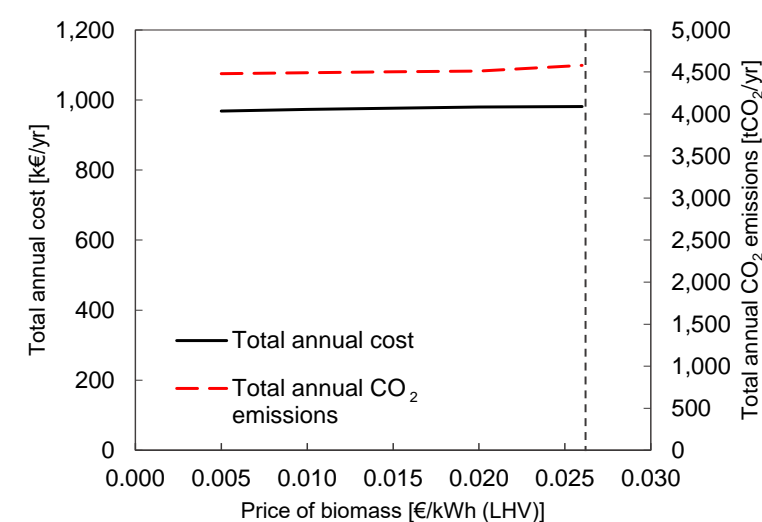

(a)

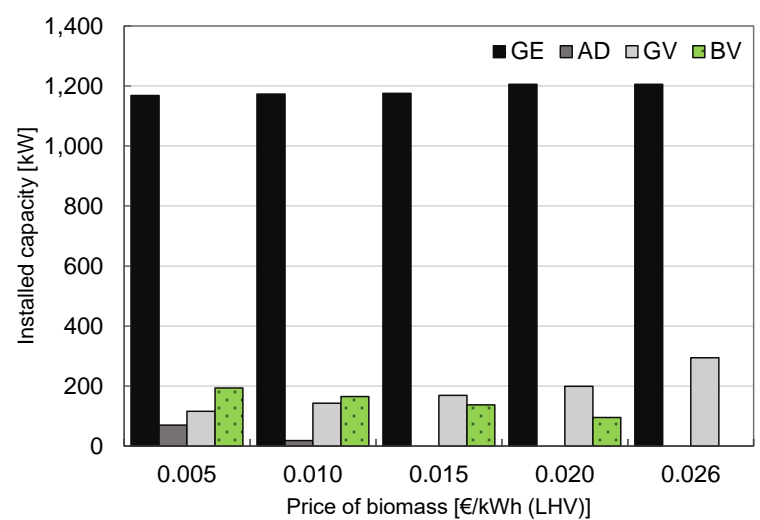

(b)

Figure 6: Sensitivity analysis of the price of biomass: (a) total annual cost (objective function) and total annual $\mathrm{CO}_{2}$ emissions, and (b) installed capacities of selected equipment.

The sensitivity analysis of the electricity purchase price $p_{e p}$ was carried out by simultaneously reducing both the on-peak $(0.136 € / \mathrm{kWh})$ and off-peak $(0.094 € / \mathrm{kWh})$ values by $20 \%, 40 \%$, and $60 \%$. Higher $p_{e p}$ values would have a similar effect as previously explained for the reduction of the $p_{\text {gas }}$. Figure 7 (a) shows the total annual cost (objective function) and total annual $\mathrm{CO}_{2}$ emissions of the optimal cost solution, and Figure 7 (b) presents the installed capacities of selected equipment, namely the cogeneration module GE, single-effect absorption chiller AS, natural gas steam boiler GV, and biomass steam boiler BV. Similar to increasing the $p_{\text {gas }}$, reducing the $p_{e p}$ negatively affected the economic feasibility of the GE. For a $20 \%$ reduction there was no change in the system configuration, the total annual cost and total annual $\mathrm{CO}_{2}$ emissions. On the other hand, for a $40 \%$ reduction, the GE was strongly reduced, being partially replaced by the $\mathrm{BV}$, resulting in a drastic increase in the total annual $\mathrm{CO}_{2}$ emissions. 


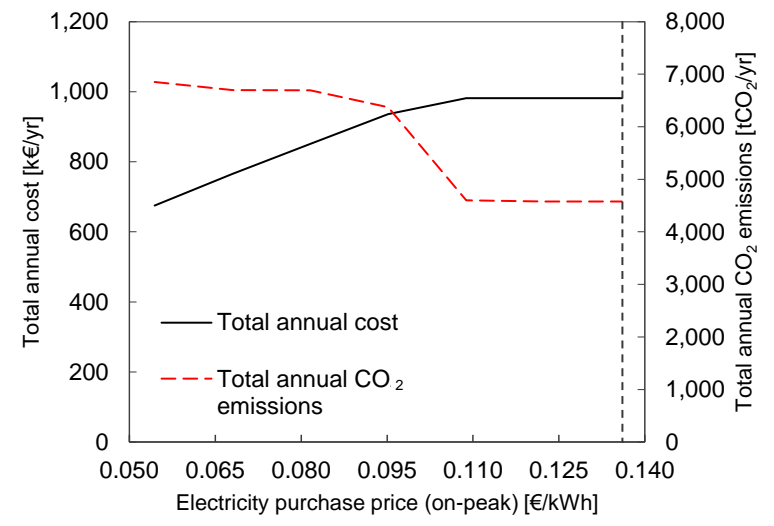

(a)

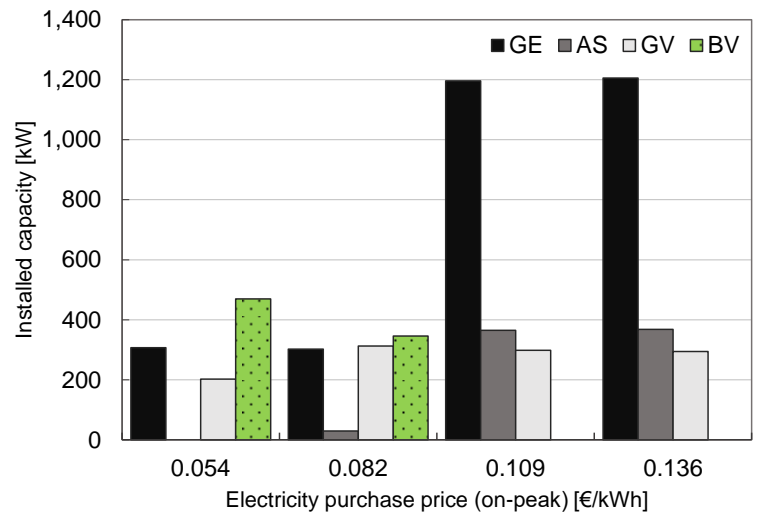

(b)

Figure 7: Sensitivity analysis of the electricity purchase price: (a) total annual cost (objective function) and total annual $\mathrm{CO}_{2}$ emissions, and (b) installed capacities of selected equipment.

\subsubsection{Sensitivity to investment costs of the RETs}

Regarding the solar RETs (i.e. photovoltaic panel PV, parabolic trough concentrator PT, and flat-plate solar thermal collector ST), it was proposed to carry out sensitivity analyses by decreasing their bare module costs $C I$ (Table 5) by $20 \%, 40 \%, 60 \%$, and $80 \%$ in the optimal cost optimization under the EECS.

The bare module cost $C I$ of the PV was varied between its initial value of 1300 and 260 $€ / \mathrm{kWp}$. Figure 8 (a) shows the total annual cost (objective function) and total annual $\mathrm{CO}_{2}$ emissions of the optimal cost solution, and Figure 8 (b) presents the installed capacities of selected equipment, namely the biomass steam boiler BV, mechanical chiller EC, singleeffect absorption chiller AS, cogeneration module GE, and photovoltaic panel PV. The PV reached the economic feasibility threshold for $C I(P V)$ values below $780 € / \mathrm{kWp}$. For $C I(P V)=$ $520 € / \mathrm{kWp}$, a significant capacity of PV was installed, almost eliminating the GE and AS, and promoting the EC and the BV. However, as previously explained, there is a saturation point associated with the EECS, so that the PV capacity leveled off for lower bare module costs. Both the total annual cost and total annual $\mathrm{CO}_{2}$ emissions were strongly reduced by the installation of PV. In addition, it is noteworthy that the installation of PV and the consequent phasing out of cogeneration have also promoted the incorporation of another RET, namely the biomass steam boiler.

In the case of the PT, its bare module cost $C I(P T)$ was varied between its initial value of 425 and $85 € / \mathrm{kW}$. Figure 9 (a) shows the total annual cost (objective function) and total annual $\mathrm{CO}_{2}$ emissions obtained for the optimal cost solution, and Figure 9 (b) presents the installed capacities of selected equipment, namely the parabolic trough concentrator PT, natural gas steam boiler GV, mechanical chiller EC, single-effect absorption chiller AS, and cogeneration module GE. The feasibility threshold lied between 170 and $85 € / \mathrm{kW}$. For a reduction of about $80 \%, C I(P T)=85 € / \mathrm{kW}$, the PT partially displaced the GV, while the GE remained unchanged. The total annual cost and total annual $\mathrm{CO}_{2}$ emissions were only marginally reduced. 


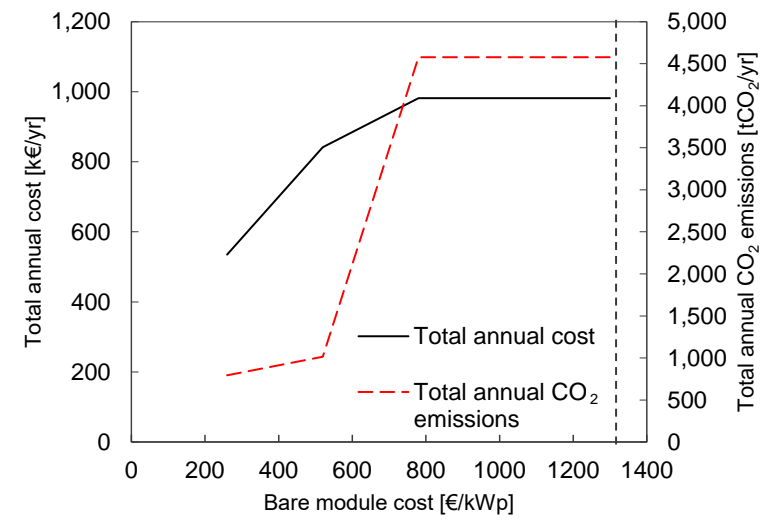

(a)

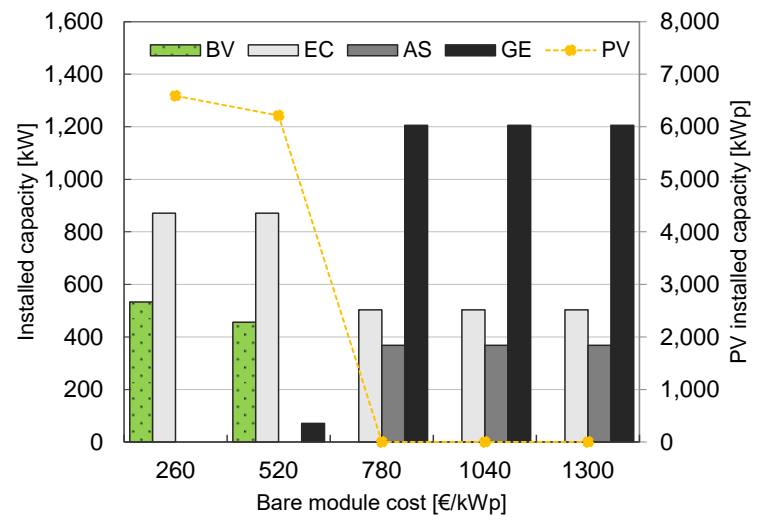

(b)

Figure 8: Sensitivity analysis of the PV bare module cost: (a) total annual cost (objective function) and total annual $\mathrm{CO}_{2}$ emissions, and (b) installed capacities of selected equipment.

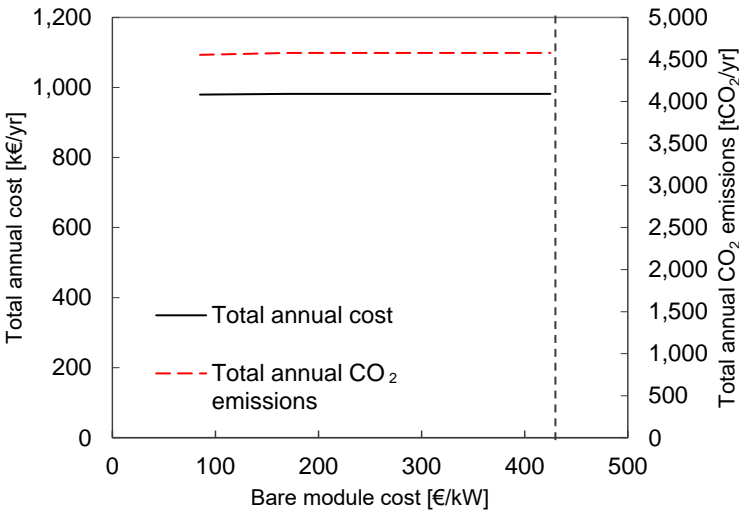

(a)

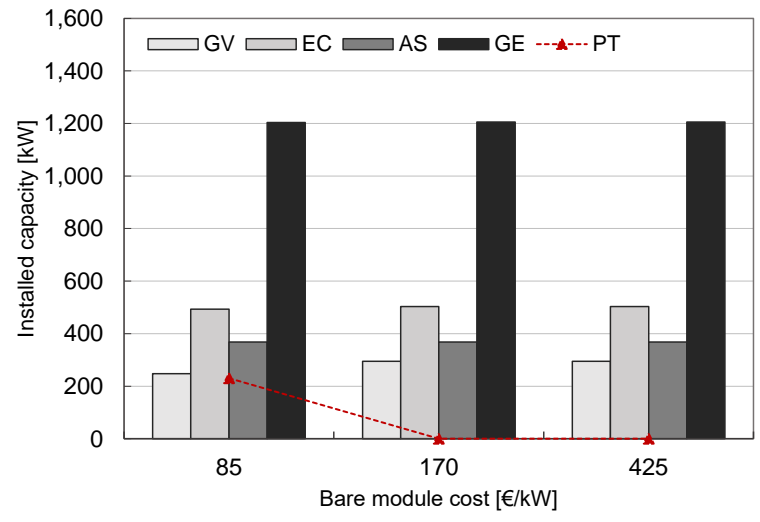

(b)

Figure 9: Sensitivity analysis of the PT bare module cost: (a) total annual cost (objective function) and total annual $\mathrm{CO}_{2}$ emissions, and (b) installed capacities of selected equipment.

As regards the ST, a sensitivity analysis was carried out by varying the $C I(S T)$ between its initial value of 500 and $100 € / \mathrm{kWp}$. However, it was never installed in the optimal cost solution under the EECS. Apart from the suggested economic disadvantage, another reason was that the hospital had a greater demand for high-temperature heat than for low-temperature heat, so that the ST would have to compete with the cogeneration module, which could simultaneously produce heat at both grades as well as electricity.

\subsubsection{Effect of a total ban on fossil fuels}

An additional situation was posed in which the fossil fuel-based technologies, namely the cogeneration module $\mathrm{GE}$ and the natural gas boilers $\mathrm{GV}$ and $\mathrm{GH}$, were not allowed to be installed in the optimal economic cost solution under the EECS ( $y I N S(G E, G V, G H)=0)$. The results obtained are shown in Table 10, along with the additional total annual cost and the total annual $\mathrm{CO}_{2}$ emissions savings relative to the reference system.

Compared to the optimal economic cost solution presented in Table 7 and Table 8, revoking the permission to install fossil fuel-based technologies led to a significant increase in both 
total annual cost (28.1\%) and total annual $\mathrm{CO}_{2}$ emissions (49.1\%), which clearly negates the environmental effectiveness of a fossil fuel ban for the present case study. As can be seen, the cogeneration module GE and natural gas steam boiler GV were replaced by the biomass steam boiler BV, cooling production became entirely electricity-based (i.e. EC with electricity purchased from the grid), and the cooling tower CT was installed to dissipate the heat rejected by the EC, hence the same load factors of both EC and CT. Because the system no longer produced and exported electricity, (i) it was required to purchase from the grid, thereby increasing the annual variable cost; and (ii) it could not displace grid related $\mathrm{CO}_{2}$ emissions, which increased the annual variable $\mathrm{CO}_{2}$ emissions of the system.

Table 10: Optimal economic cost solution without fossil fuel-based technologies.

\begin{tabular}{|c|c|c|c|}
\hline \multirow[b]{2}{*}{ Results } & \multicolumn{3}{|c|}{ Modality D (EECS) } \\
\hline & $\begin{array}{l}P I N, \\
\text { kW }\end{array}$ & $\begin{array}{c}f u, \\
\%\end{array}$ & $\begin{array}{l}\text { Z, } \\
\mathbf{k} €\end{array}$ \\
\hline BV & 808 & 73.20 & 302.9 \\
\hline $\mathrm{EC}$ & 871 & 62.34 & 91.4 \\
\hline $\mathrm{CT}$ & 1,013 & 62.34 & 30.4 \\
\hline $\mathrm{HS}, \mathrm{kWh}$ & 49 & - & 2.0 \\
\hline $\mathrm{CS}, \mathrm{kWh}$ & 8 & - & 0.7 \\
\hline Investment cost, $€$ & & & 427,338 \\
\hline Annual variable $\mathrm{CO}_{2}$ emissions, $\mathrm{kg} \mathrm{CO}_{2} / \mathrm{yr}$ & & & $6,816,127$ \\
\hline Annual fixed $\mathrm{CO}_{2}$ emissions, $\mathrm{kg} \mathrm{CO}_{2} / \mathrm{yr}$ & & & 9,535 \\
\hline Total annual $\mathrm{CO}_{2}$ emissions, $\mathrm{kg} \mathrm{CO}_{2} / \mathrm{yr}$ & & & $6,825,662$ \\
\hline Annual variable cost, $€ / \mathrm{yr}$ & & & $1,179,966$ \\
\hline Annual fixed cost, $€ / y r$ & & & 76,921 \\
\hline Total annual cost, $€ /$ yr & & & $1,256,887$ \\
\hline Total annual cost increase (reference system), $€ / \mathrm{yr}$ & & & 642 \\
\hline Total annual $\mathrm{CO}_{2}$ emissions savings (reference system), $\mathrm{kg} \mathrm{CO}_{2} / \mathrm{yr}$ & & & 815,794 \\
\hline
\end{tabular}

Nevertheless, the optimal cost solution without fossil fuels could be regarded as an interesting alternative to the reference system, as with practically the same total annual cost $(0.05 \%$ increase), the total annual $\mathrm{CO}_{2}$ emissions could be reduced by $10.7 \%$. The main difference was that the natural gas boilers $\mathrm{GH}$ and $\mathrm{GV}$ in the reference system were replaced by the biomass steam boiler BV in the optimal cost system. The increased investment cost due to the costlier BV was partially compensated by the lower annual operation costs from the cheaper biomass resource. As a consequence, the total annual cost remained practically unchanged (increased only $0.05 \%$ ). On the bright side, consuming biomass instead of natural gas has brought total annual $\mathrm{CO}_{2}$ emissions down.

\subsection{Environmental optimal solutions}

The optimization model was solved for the environmental aspect (total annual $\mathrm{CO}_{2}$ emissions). Table 11 and Table 12 show the results obtained for the optimal environmental solutions under modalities A through D (see Table 6), as well as the reference system, which is the same one analyzed in Section 3.1. 
It has been previously pointed out that by selling or exporting electricity to the grid, the system displaced grid related $\mathrm{CO}_{2}$ emissions, which proved to be an important way to reduce total annual $\mathrm{CO}_{2}$ emissions even in the case of electricity produced in the cogeneration module with natural gas. For the environmental optimization, this capability was best coupled with modalities C (unrestricted sale) and D (EECS), which allowed the systems to sell or inject as much electricity as they could. Indeed, the optimal solutions under those modalities reached the lowest total annual $\mathrm{CO}_{2}$ emissions, which were negative values, meaning that the systems displaced more $\mathrm{CO}_{2}$ emissions than they generated. The same system configurations were obtained for modalities $\mathrm{C}$ and $\mathrm{D}$, in which the installed capacities of cogeneration module GE and photovoltaic panel PV were maximized, reaching their maximum installable capacities $P I N_{M A X}$. Consequently, given the oversized GE and PV capacities, no other RET was installed, and cooling production was entirely electricity-based (i.e. EC with selfgenerated electricity). Nevertheless, it should be noted that the operation of the GE to maximize electricity production resulted in a large quantity of dissipated cogeneration heat, so that the minimum legal requirement of $15 \%$ (Eq. (29)) was reached.

When there were limits to the sale of electricity, as in modalities A (purchase only) and B (annual consumer), then: (i) a more diverse set of technologies was included, particularly RETs such as PV, parabolic trough concentrator PT, and biomass steam boiler BV; (ii) relevant installed capacities of TES units were included; and (iii) the obtained total annual $\mathrm{CO}_{2}$ emissions were higher than under modalities $\mathrm{C}$ and $\mathrm{D}$. It is noteworthy that the GE was environmentally interesting even when the system was not allowed to sell electricity to the grid (modality A). Moreover, apart from the previously mentioned correspondence between the GE and the AS, modalities A and B also highlighted the positive synergy between the PT and the AD.

Compared with the reference system, the optimal environmental solutions could significantly reduce total annual $\mathrm{CO}_{2}$ emissions, as shown in Table 13. The greater the flexibility of the system to sell or export electricity to the grid, the higher the annual $\mathrm{CO}_{2}$ emissions savings. Indeed, modalities $C$ and $D$ were the ones with the highest reductions of about $232.6 \%$. It should be noted that the optimal solutions under modalities $\mathrm{C}$ and $\mathrm{D}$ were essentially the same except for the total annual cost, which was much higher for modality D because, as explained, there was no revenue from electricity sale. Consequently, while the payback period for modality $\mathrm{C}$ was about 8.1 years, the lowest of the four modalities, the system under modality $\mathrm{D}$ was not profitable with respect to the reference system, as there were no annual variable cost savings to compensate the additional investment cost. Since the required investment costs and payback periods were very high, it would be interesting to investigate trade-off solutions between both economic and environmental criteria, in search for acceptable solutions. By dividing the additional total annual cost by the annual $\mathrm{CO}_{2}$ emissions savings, the unit cost of $\mathrm{CO}_{2}$ emissions reduction is obtained. 
Table 11: Environmental optimization - Reference system and optimal environmental polygeneration systems layouts.

\begin{tabular}{|c|c|c|c|c|c|c|c|c|c|c|c|c|c|c|c|}
\hline \multirow{2}{*}{$\begin{array}{c}\text { Technology } \\
t\end{array}$} & \multicolumn{3}{|c|}{ Reference system } & \multicolumn{3}{|c|}{ A - Purchase only } & \multicolumn{3}{|c|}{ B - Annual consumer } & \multicolumn{3}{|c|}{ C - Unrestricted sale } & \multicolumn{3}{|c|}{ D - EECS } \\
\hline & $\begin{array}{l}P I N, \\
\text { kW }\end{array}$ & $\begin{array}{c}f u, \\
\%\end{array}$ & $\begin{array}{l}\mathrm{ZCO}, \\
\mathrm{tCO}_{2}\end{array}$ & $\begin{array}{l}P I N, \\
\text { kW }\end{array}$ & $\begin{array}{c}f u, \\
\%\end{array}$ & $\begin{array}{l}\mathrm{ZCO}, \\
\mathrm{tCO}_{2}\end{array}$ & $\begin{array}{l}P I N, \\
\mathrm{~kW}\end{array}$ & $\begin{array}{c}f u, \\
\%\end{array}$ & $\begin{array}{l}\mathrm{ZCO} 2, \\
\mathrm{tCO}_{2}\end{array}$ & $\begin{array}{l}P I N, \\
\text { kW }\end{array}$ & $\begin{array}{c}f u, \\
\%\end{array}$ & $\begin{array}{c}\mathrm{ZCO} 2 \\
\mathrm{tCO}_{2}\end{array}$ & $\begin{array}{l}P I N, \\
\text { kW }\end{array}$ & $\begin{array}{c}f u, \\
\%\end{array}$ & $\begin{array}{c}\mathrm{ZCO} 2 \\
\mathrm{tCO}_{2}\end{array}$ \\
\hline GE & - & - & - & 1,344 & 44.26 & 87.4 & 0 & - & 0.0 & 5,000 & 90.14 & 325.0 & 5,000 & 90.14 & 325.0 \\
\hline PV & - & - & - & 4,343 & 12.75 & $7,991.9$ & 6,237 & 18.83 & $1,1475.9$ & 10,000 & 18.83 & $18,400.0$ & 10,000 & 18.83 & $18,400.0$ \\
\hline PT & - & - & - & 3,997 & 10.50 & 519.7 & 3,545 & 10.73 & 460.8 & 0 & - & 0.0 & 0 & - & 0.0 \\
\hline ST & - & - & - & 0 & - & 0.0 & 0 & - & 0.0 & 0 & - & 0.0 & 0 & - & 0.0 \\
\hline $\mathrm{GH}$ & 76 & 1.56 & 0.8 & 0 & - & 0.0 & 0 & - & 0.0 & 0 & - & 0.0 & 0 & - & 0.0 \\
\hline GV & 780 & 75.61 & 7.8 & 0 & - & 0.0 & 0 & - & 0.0 & 0 & - & 0.0 & 0 & - & 0.0 \\
\hline $\mathrm{BH}$ & - & - & - & 0 & - & 0.0 & 0 & - & 0.0 & 0 & - & 0.0 & 0 & - & 0.0 \\
\hline BV & - & - & - & 535 & 30.02 & 10.7 & 756 & 42.98 & 15.1 & 0 & - & 0.0 & 0 & - & 0.0 \\
\hline $\mathrm{EC}$ & 879 & 61.75 & 140.7 & 337 & 28.43 & 54.0 & 745 & 51.25 & 119.2 & 0 & - & 0.0 & 0 & - & 0.0 \\
\hline AS & - & - & - & 372 & 55.39 & 61.4 & 0 & - & 0.0 & 879 & 61.75 & 145.1 & 879 & 61.75 & 145.1 \\
\hline $\mathrm{AD}$ & - & - & - & 600 & 40.15 & 99.0 & 528 & 30.51 & 87.0 & 0 & - & 0.0 & 0 & - & 0.0 \\
\hline $\mathrm{CT}$ & 1,023 & 61.75 & 25.6 & 1,574 & 71.05 & 39.4 & 1,180 & 61.06 & 29.5 & 5,058 & 84.27 & 126.4 & 5,058 & 84.27 & 126.4 \\
\hline $\mathrm{HS}, \mathrm{kWh}$ & - & - & - & 43 & - & 6.5 & 469 & - & 70.4 & 0 & - & 0.0 & 0 & - & 0.0 \\
\hline $\mathrm{CS}, \mathrm{kWh}$ & - & - & - & 667 & - & 200.1 & 0 & - & 0.0 & 0 & - & 0.0 & 0 & - & 0.0 \\
\hline Embodied $\mathrm{CO}_{2}$ emissions, $\mathrm{tCO}_{2}$ & & & 174.8 & & & $9,069.9$ & & & $12,258.0$ & & & $18,996.5$ & & & $18,996.5$ \\
\hline
\end{tabular}


Table 12: Environmental optimization - Main results for the reference system and optimal environmental polygeneration systems.

\begin{tabular}{|c|c|c|c|c|c|}
\hline Results & Reference system & A - Purchase only & B - Annual consumer & C-Unrestricted sale & D - EECS \\
\hline Natural gas, MWh/yr & $5,567,170$ & $11,150,053$ & 0 & $84,454,031$ & $84,454,031$ \\
\hline Biomass, MWh/yr & - & $1,653,456$ & $3,347,518$ & 0 & 0 \\
\hline Purchased electricity, MWh/yr & $10,465,556$ & 0 & $5,221,597$ & 0 & 0 \\
\hline Sold electricity, MWh/yr & - & - & $5,221,597$ & $44,947,470$ & - \\
\hline Imported electricity, MWh/yr & - & - & - & - & 0 \\
\hline Exported electricity, MWh/yr & - & - & - & - & $44,947,470$ \\
\hline Natural gas, $\mathrm{kg} \mathrm{CO}_{2} / \mathrm{yr}$ & $1,124,568$ & $2,252,311$ & 0 & $17,059,714$ & $17,059,714$ \\
\hline Biomass, $\mathrm{kg} \mathrm{CO}_{2} / \mathrm{yr}$ & - & 83,615 & 169,284 & 0 & 0 \\
\hline Purchased electricity, $\mathrm{kg} \mathrm{CO}_{2} / \mathrm{yr}$ & $6,508,147$ & 0 & $3,259,317$ & 0 & 0 \\
\hline Sold electricity, $\mathrm{kg} \mathrm{CO}_{2} / \mathrm{yr}$ & - & - & $-3,244,251$ & $-28,143,031$ & - \\
\hline Imported electricity, $\mathrm{kg} \mathrm{CO}_{2} / \mathrm{yr}$ & - & - & - & - & 0 \\
\hline Exported electricity, $\mathrm{kg} \mathrm{CO}_{2} / \mathrm{yr}$ & - & - & - & - & $-28,143,031$ \\
\hline Annual variable $\mathrm{CO}_{2}$ emissions, $\mathrm{kg} \mathrm{CO}_{2} / \mathrm{yr}$ & $7,632,715$ & $2,335,926$ & 184,350 & $-11,083,317$ & $-11,083,317$ \\
\hline Annual fixed $\mathrm{CO}_{2}$ emissions, $\mathrm{kg} \mathrm{CO}_{2} / \mathrm{yr}$ & 8,741 & 453,494 & 612,899 & 949,825 & 949,825 \\
\hline Total annual $\mathrm{CO}_{2}$ emissions, $\mathrm{kg} \mathrm{CO}_{2} / \mathrm{yr}$ & $7,641,456$ & $2,789,420$ & 797,249 & $-10,133,491$ & $-10,133,491$ \\
\hline Natural gas, $€ / \mathrm{yr}$ & 194,851 & 390,252 & 0 & $2,955,891$ & $2,955,891$ \\
\hline Biomass, $€ / \mathrm{yr}$ & - & 42,990 & 87,035 & 0 & 0 \\
\hline Purchased electricity, $€ / \mathrm{yr}$ & $1,021,641$ & 0 & 528,685 & 0 & 0 \\
\hline Sold electricity, $€ / \mathrm{yr}$ & - & - & $-428,171$ & $-3,777,999$ & - \\
\hline Annual variable cost, $€ / \mathrm{yr}$ & $1,216,492$ & 433,242 & 187,550 & $-822,108$ & $2,955,891$ \\
\hline Annual fixed cost, $€ / \mathrm{yr}$ & 39,753 & $1,591,867$ & $1,830,151$ & $3,015,958$ & $3,015,958$ \\
\hline Total annual cost, $€ / \mathrm{yr}$ & $1,256,245$ & $2,025,109$ & $2,017,701$ & $2,193,850$ & $5,971,849$ \\
\hline Investment cost, $\mathrm{k} €$ & 220.8 & $8,843.7$ & $10,167.5$ & $16,755.3$ & $16,755.3$ \\
\hline GE annual heat efficiency & - & $39.8 \%$ & - & $15.0 \%$ & $15.0 \%$ \\
\hline
\end{tabular}


Table 13: Optimal environmental solutions relative to the reference system.

\begin{tabular}{lrrrr}
\hline \multicolumn{1}{c}{ Result } & $\begin{array}{c}\text { A - Purchase } \\
\text { only }\end{array}$ & $\begin{array}{c}\text { B - Annual } \\
\text { consumer }\end{array}$ & $\begin{array}{r}\text { C - Unrestricted } \\
\text { sale }\end{array}$ & D - EECS \\
\hline Additional investment cost, $\mathrm{k} €$ & $8,622.9$ & $9,946.7$ & $16,534.5$ & $16,534.5$ \\
Annual variable cost savings, $\mathrm{k} € / \mathrm{yr}$ & 783.3 & $1,028.9$ & $2,038.6$ & $-1,739.4$ \\
Payback period, yr & 11.0 & 9.7 & 8.1 & - \\
Annual $\mathrm{CO}_{2}$ emissions savings, & $4,852.0$ & $6,844.2$ & $17,774.9$ & $17,774.9$ \\
$\mathrm{tCO} 2 / \mathrm{yr}$ & $63.5 \%$ & $89.6 \%$ & $232.6 \%$ & $232.6 \%$ \\
Annual $\mathrm{CO}_{2}$ emissions savings, $\%$ & 768.9 & 761.5 & 937.6 & $4,715.6$ \\
Additional total annual cost, $\mathrm{k} € / \mathrm{yr}$ & 158.5 & 111.3 & 52.7 & 265.3 \\
Unit cost of $\mathrm{CO}_{2}$ emissions & & & & \\
reduction, $€ / \mathrm{tCO}_{2}$ & & & & \\
\hline
\end{tabular}

\subsection{On the sensitiveness to the electric grid $\mathrm{CO}_{2}$ emissions}

In the present study, the environmental criterion was described in terms of the $\mathrm{CO}_{2}$ emissions associated with the manufacturing of the installed technologies and generated during the operation of the system through the consumption of electricity, natural gas, and biomass. As explained in Section 2.2.3, hourly $\mathrm{CO}_{2}$ emission factors of the grid electricity $\mathrm{kgCO} 2_{\text {ele }}$ were employed with an annual average value equal to $0.6238 \mathrm{~kg} \mathrm{CO}_{2} / \mathrm{kWh}$, corresponding to the emissions generated at the margin of operation and provided by the Brazilian Ministry of Science, Technology, Innovation and Communications [68]. However, the annual average $\mathrm{CO}_{2}$ emission factor of the Brazilian electric system as a whole is about four times lower $(0.1581 \mathrm{~kg} \mathrm{CO} / \mathrm{kWh})$.

Among other factors, the use of those high values of the grid $\mathrm{CO}_{2}$ emission factors has led to some surprising results, such as: (i) the ability of the system to displace grid emissions with electricity produced in the GE with natural gas, so that the optimal environmental solutions under modalities C (unrestricted sale) and D (EECS) maximized the installed capacity of GE to the detriment of a more rational use of the cogenerated heat (see Section 3.3); (ii) the increase in $\mathrm{CO}_{2}$ emissions caused by a ban on fossil fuel-based technologies (see Table 10); and (iii) the increase in $\mathrm{CO}_{2}$ emissions caused by higher natural gas purchase prices (see Figure 5). Therefore, it was proposed to carry out a sensitivity analysis of the hourly $\mathrm{kgCO} 2$ ele in the optimal environmental solution under the Brazilian EECS. In terms of annual average values, the $\mathrm{kgCO} 2_{\text {ele }}$ were reduced between 0.6238 and $0.1581 \mathrm{~kg} \mathrm{CO}_{2} / \mathrm{kWh}$.

Figure 10 (a) shows the total annual cost and total annual $\mathrm{CO}_{2}$ emissions (objective function) obtained for the optimal environmental solution under modality D, and Figure 10 (b) presents the installed capacities of selected equipment, namely the biomass steam boiler BV, doubleeffect absorption chiller AD, mechanical chiller EC, single-effect absorption chiller AS, cogeneration module GE, photovoltaic panel PV, and parabolic trough concentrator PT. 


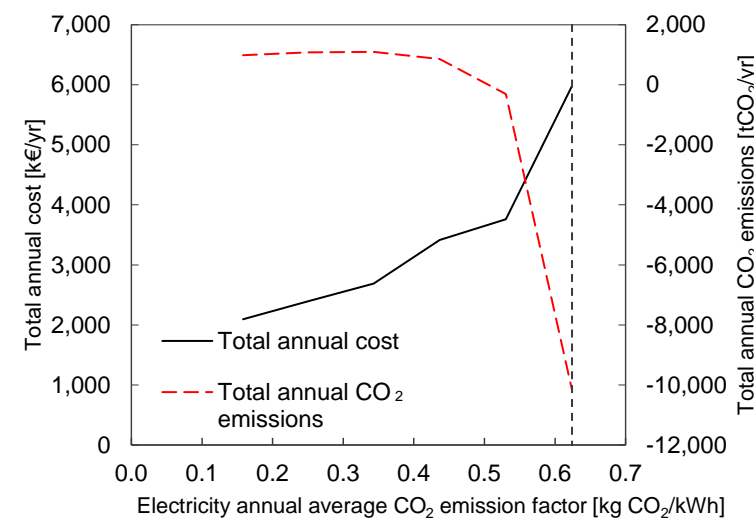

(a)

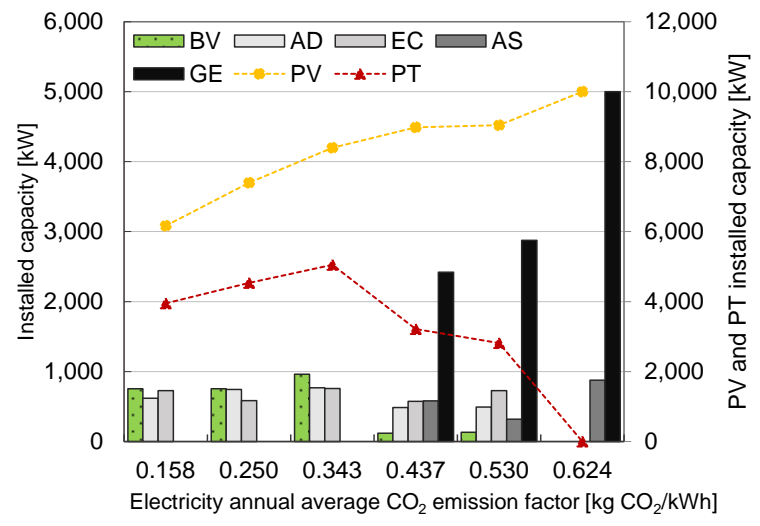

(b)

Figure 10: Sensitivity analysis of the electricity $\mathrm{CO}_{2}$ emission factors under the EECS: (a) total annual cost and total annual $\mathrm{CO}_{2}$ emissions (objective function), and (b) installed capacities of selected equipment.

The results show that the $\mathrm{kgCO} 2_{\text {ele }}$ had a huge influence on both the total annual $\mathrm{CO}_{2}$ emissions and total annual cost of the system. Reducing the $\mathrm{kgCO} 2_{\text {ele }}$ displaced cogeneration, which explains the increase in total annual $\mathrm{CO}_{2}$ emissions (i.e. less electricity was exported to the grid to displace grid related $\mathrm{CO}_{2}$ emissions) and the decrease in total annual cost (i.e. reduced cost with natural gas consumption). Therefore, as the $\mathrm{kgCO} 2_{\text {ele }}$ shifted from the margin of operation to the national average, GE was no longer a viable option to mitigate grid $\mathrm{CO}_{2}$ emissions, being completely phased out with a $45 \%$ reduction in $\mathrm{kgCO} 2_{\text {ele }}$. Besides, even the PV was partially displaced by lower grid emissions.

It is worth noting that high values of $\mathrm{kgCO} 2_{\text {ele }}$, close to the margin of operation, result in optimal environmental solutions with negative total annual $\mathrm{CO}_{2}$ emissions, which means, as explained, that the system displaces more $\mathrm{CO}_{2}$ emissions than it generates. On the other hand, for lower $\mathrm{kgCO}_{2}$ ele, the optimal environmental solutions present positive total annual $\mathrm{CO}_{2}$ emissions. Taking the current national average $\mathrm{kgCO} 2_{\text {ele }}$, the optimal environmental solution under the EECS would be similar to that under modality B (Table 11 and Table 12), consisting of a diverse set of RETs, namely PV, PT and BV, electricity- and heat-driven cooling devices (i.e. EC and AD, respectively), and the electric grid as support.

\section{Discussion}

The synthesis model proposed in Section 2 was described in a stepwise procedure that can be adapted to other case studies. In this regard, the hospital facility is a particular type of building characterized by regular occupancy and long operating hours, as well as for a significant demand for high-quality thermal energy (i.e. saturated steam at $180{ }^{\circ} \mathrm{C}$ ). These aspects favor cogeneration, which is a dispatchable generation unit that can offer heat at different temperature levels with reliability and cost-efficiency. On the other hand, residential, commercial center, and university buildings, to name a few examples, present fundamentally different energy demand profiles and tend to require thermal energy at lower temperatures. Thus, the superstructure should be modified accordingly, in which case the steam boilers 
would be less relevant, and it would be interesting to incorporate an electric heat pump to allow for hot water production using electricity. The synthesis model can also be applied to buildings in other regions or countries, in which case the local conditions (e.g. energy prices, solar availability, ambient air temperature, legal constraints) must be previously obtained. More particularly, it could be interesting to assess how the same regulatory framework might have different impacts depending on climate zones within the same country. Finally, this discussion highlights the particularity of the integrated synthesis and operation optimization procedure.

The application of the synthesis model to the case study of the Brazilian university hospital in Section 3 allowed to illustrate through a concrete example how legal constraints affect the integration of cogeneration and RETs in polygeneration systems for buildings. It is important to understand that the synthesis procedure is always tailored to the application's specific circumstances. For this reason, the obtained results are not directly comparable with other cases, but they provide insights that can be extended to other studies.

The analysis of the optimal cost solution showed the technical, economic, and environmental feasibility of the polygeneration system relative to a conventional energy system. The gas engine cogeneration module GE was an attractive solution to cover the hospital's electricity and thermal loads. Those results are in line with the literature about the potential viability of properly integrated energy systems for hospital facilities [14,19]. Moreover, the installed capacity of GE decreased from modalities C (unrestricted sale) to D (EECS). A similar effect has been observed by Lozano et al. [52] with the self-consumption obligation imposed on cogeneration systems in Spain.

The net metering mechanism in Brazil, also called EECS, was not successful at the objective of including RETs in the considered case study. This result is in accordance with published research [36,71], which have stressed that net metering has historically been insufficient on its own to promote renewables. In this context, it is important to understand some of the conditions that enable this mechanism to be profitable for consumers. First, the costs of covering the energy demands with the system must be lower than purchasing electricity from the grid. Second, the system must be able to consume back the exported electricity, which might limit the uptake of RETs. In fact, the sensitivity analysis showed that PV was only installed when its bare module cost was reduced to $780 € / \mathrm{kW}_{\mathrm{p}}(40 \%$ reduction) and stopped growing as the system reached a saturation point.

Currently, there is a wide debate about the need to reform self-consumption schemes $[89,90]$, as an increasing amount of distributed generation systems are connected to the grid, particularly at distribution level. One of the main issues of the net metering scheme is that energy credits compensate the electricity bill as a whole, thereby exempting the consumer from paying grid tariffs and taxes even though they remain connected to the distribution network. As a result, higher shares of the electric system cost are allocated to the other nonproducing consumers.

In the Brazilian electricity sector, the ANEEL has been carrying out public hearings to gather contributions for the next net metering regulatory update [91]. Five alternatives to the current 
modality are under consideration. The difference is given by the amount of electricity that can be compensated, which is progressively reduced as less tariff components are compensated (e.g. distribution tariff, energy tariff, levies, losses). As a consequence, the revised version of the net metering regulation is expected to reduce the attractiveness of the injected electricity which, in turn, might compromise the feasibility of cogeneration and RETs.

From the environmental perspective, an important aspect to consider is that Brazil has a very high share of renewable electricity, reaching $83 \%$ of total electricity generation in 2019 , with hydropower, wind, and biomass accounting for $64.9 \%, 8.6 \%$, and $8.4 \%$, respectively [92]. In this context, the annual average $\mathrm{CO}_{2}$ emission factor of the national electric system is estimated at $0.1581 \mathrm{~kg} \mathrm{CO}_{2} / \mathrm{kWh}$ [68]. Because of such low grid emission factor, it is useful to consider the emissions that would be displaced at the margin of the operation by new facilities. Those are the emissions considered in this study, which were given in Section 2.2.3. Following the methodological tool "Tool to calculate the emission factor for an electricity system", the Ministry in Brazil calculates the hourly $\mathrm{CO}_{2}$ emission factor for the displacement of electricity generated by power plants at the operating margin (group of existing plants whose current electricity production would be affected by the proposed new system) and at the build margin (group of prospective plants whose construction and future operation would be affected by the proposed new system). The resulting annual average value is $0.6238 \mathrm{~kg}$ $\mathrm{CO}_{2} / \mathrm{kWh}$, almost four times greater than the emissions of the grid taken as a whole.

The $\mathrm{CO}_{2}$ emission factors of the electricity at the margin of operation were so high that they enabled the implementation of other less polluting fossil fuels, such as natural gas, in the environmental optimal solutions. This implies that natural gas-based cogeneration in Brazil stands out as a transition technology, since indeed it does emit less $\mathrm{CO}_{2}$ emissions than the power plants at the operating margin. However, as grid $\mathrm{CO}_{2}$ emissions reduce over time, the environmental contribution of the GE will diminish too, until it is no longer interesting. In fact, the sensitivity analysis showed that the GE was completely phased out when grid $\mathrm{CO}_{2}$ emissions were reduced by $45 \%$. Therefore, based on the considerable interest of the cogeneration gas engine for the Brazilian hospital, future research could evaluate the use of biogas instead of natural gas in renewable polygeneration systems as a way to achieve a carbon neutral energy supply. The technological development and energy potential of this biofuel for distributed generation purposes in Brazil have been assessed by Ferreira et al. [93] and Freitas et al. [94].

The total ban on fossil fuels did not prove to be a good policy to promote RETs because their implementation in the cost optimal solution depends on their economic profitability. This is a similar situation to the one explained for the net metering scheme. In this particular case, revoking the permission to install the GE and the natural gas boilers left the solar thermal collectors and the biomass boilers as the only options for thermal energy production, so the system installed the biomass steam boiler because it was the cheapest alternative. In addition, because the total ban on fossil fuels was assessed from the economic cost perspective, the optimal solution was not affected by the grid $\mathrm{CO}_{2}$ emission factors. This implies that this policy should include other perspectives as well as the purely economic. So, instead of focusing on a mere prohibition of fossil fuels, efforts could be oriented towards improving the 
profitability of RETs, implementing a requirement of minimum renewable fraction and/or promoting flexibility through energy storage systems.

Regarding the qualified cogeneration constraint, the results show that it has not been an issue for the economic cost solutions since the GE annual heat efficiency values were way above the minimum requirement of $15 \%$ imposed by Eq. (29). Nevertheless, for the environmental criterion the minimum limit was reached, whereby the engine operated under a power unit mode, maximizing electricity production to the detriment of a more rational use of the cogenerated heat. Similar observations were made in a previous study by Pina et al [55] in CHP and CCHP systems for the same Brazilian hospital, and by Piacentino et al. [38]. While this operational strategy allowed total annual $\mathrm{CO}_{2}$ emissions to be minimized, it represents an unrealistic scenario. Therefore, in line with our previous claim about the natural gas cogeneration module as a transition technology, the general requirements for the qualification of cogeneration facilities in Brazil could be revised to include better opportunities for RETs.

\section{Conclusions}

This paper highlights the need for detailed considerations of legal constraints in the optimal design of polygeneration systems. In this context, a comprehensive synthesis model is proposed to determine the optimal system configuration and hourly operational planning of polygeneration systems integrating renewable energy technologies for buildings. The model includes different types of local policies, such as power exchange modalities, subsidies and surcharges on energy resources prices and investment costs, and a total ban on fossil fuels. A university hospital in Brazil is used as case study, and the Brazilian net metering scheme is taken into account. The application of the synthesis model to the case study in Brazil allowed to illustrate through a concrete example how legal constraints affect the technical, economic, and environmental feasibility of cogeneration and RETs.

By following the stepwise procedure described, the synthesis model can be adapted to other applications and countries. Thus, the model presented herein can help investors and policy makers to make informed decisions. Finally, the knowledge acquired in the literature survey combined with the analyses carried out in this paper, provide some insights that can be useful to other researchers and policy makers in Brazil and in other countries:

- Support policies should be multifaceted. The net metering mechanism in Brazil was not effective by itself at the goal of promoting RETs. Therefore, future regulatory revisions could explicitly address renewable electricity integration and include a more comprehensive support plan to deliver sustained long-term incentives.

- Natural gas cogeneration is a relevant option in the transition to a decarbonized energy system. Therefore, the requirements for qualified cogeneration could be revised to explicitly include a minimum renewable fraction requirement.

- More policy attention should be given to renewable heat and renewable cooling. Researchers and policy makers tend to focus on renewable electricity policies and on electrification, but alternative production trajectories should also be studied, such as cooling production in absorption chillers driven by renewable (solar or biomass) or cogenerated heat. 


\section{Acknowledgments}

This work was developed in the frame of the research project ENE2017-87711-R, partially funded by the Spanish Government (Energy Program), the Government of Aragon (Ref: T5517R), Spain, and the EU Social Fund (FEDER Program 2014-2020 "Building Europe from Aragon"). Eduardo Pina acknowledges financial support from the Brazilian Federal Government and CNPq Science Without Borders Program.

\section{References}

[1] IEA. World Energy Balances 2019 2019. https://www.iea.org/subscribe-to-data-services/world-energybalances-and-statistics (accessed August 7, 2020).

[2] EIA. Global energy consumption driven by more electricity in residential, commercial buildings. Today in Energy 2019. https://www.eia.gov/todayinenergy/detail.php?id=41753 (accessed June 9, 2020).

[3] IEA. Fuels and Technologies: Cooling 2020. https://www.iea.org/fuels-and-technologies/cooling (accessed May 23, 2020).

[4] EPE. NOTA TÉCNICA EPE 030/2018 - Uso de Ar Condicionado no Setor Residencial Brasileiro: Perspectivas e contribuições para o avanço em eficiência energética. 2018.

[5] Forrester SP. Residential cooling load impacts on Brazil's electricity demand. 2019.

[6] Wu DW, Wang RZ. Combined cooling, heating and power: A review. Prog Energy Combust Sci 2006;32:459-95. https://doi.org/10.1016/j.pecs.2006.02.001.

[7] Liu M, Shi Y, Fang F. Combined cooling, heating and power systems: A survey. Renew Sustain Energy Rev 2014;35:1-22. https://doi.org/10.1016/j.rser.2014.03.054.

[8] Serra LM, Lozano MA, Ramos J, Ensinas A V., Nebra SA. Polygeneration and efficient use of natural resources. Energy 2009;34:575-86. https://doi.org/10.1016/j.energy.2008.08.013.

[9] Pepermans G, Driesen J, Haeseldonckx D, Belmans R, D’haeseleer W. Distributed generation: definition, benefits and issues. Energy Policy 2005;33:787-98. https://doi.org/10.1016/j.enpol.2003.10.004.

[10] Mancarella P. MES (multi-energy systems): An overview of concepts and evaluation models. Energy 2014;65:1-17. https://doi.org/10.1016/j.energy.2013.10.041.

[11] Jana K, Ray A, Majoumerd MM, Assadi M, De S. Polygeneration as a future sustainable energy solution - A comprehensive review. Appl Energy 2017;202:88-111. https://doi.org/10.1016/j.apenergy.2017.05.129.

[12] Rong A, Lahdelma R. Role of polygeneration in sustainable energy system development challenges and opportunities from optimization viewpoints. Renew Sustain Energy Rev 2016;53:363-72. https://doi.org/10.1016/j.rser.2015.08.060.

[13] Santo DB do E. An energy and exergy analysis of a high-efficiency engine trigeneration system for a hospital: A case study methodology based on annual energy demand profiles. Energy Build 2014;76:18598. https://doi.org/10.1016/j.enbuild.2014.02.014.

[14] Lozano MA, Ramos JC, Carvalho M, Serra LM. Structure optimization of energy supply systems in tertiary sector buildings. Energy Build 2009;41:1063-75. https://doi.org/10.1016/j.enbuild.2009.05.008.

[15] Li L, Mu H, Li N, Li M. Economic and environmental optimization for distributed energy resource systems coupled with district energy networks. Energy 2016;109:947-60. https://doi.org/10.1016/j.energy.2016.05.026.

[16] Martinez S, Michaux G, Salagnac P, Bouvier J. Micro-combined heat and power systems (micro-CHP) based on renewable energy sources. Energy Convers Manag 2017;154:262-85. https://doi.org/10.1016/j.enconman.2017.10.035.

[17] Murugan S, Horák B. A review of micro combined heat and power systems for residential applications. Renew Sustain Energy Rev 2016;64:144-62. https://doi.org/10.1016/j.rser.2016.04.064.

[18] Chicco G, Mancarella P. Distributed multi-generation: A comprehensive view. Renew Sustain Energy Rev 2009;13:535-51. https://doi.org/10.1016/j.rser.2007.11.014. 
[19] Yang G, Zhai XQ. Optimal design and performance analysis of solar hybrid CCHP system considering influence of building type and climate condition. Energy 2019;174:647-63. https://doi.org/10.1016/j.energy.2019.03.001.

[20] Liu P, Georgiadis MC, Pistikopoulos EN. An energy systems engineering approach for the design and operation of microgrids in residential applications. Chem Eng Res Des 2013;91:2054-69. https://doi.org/10.1016/j.cherd.2013.08.016.

[21] Wakui T, Kawayoshi H, Yokoyama R. Optimal structural design of residential power and heat supply devices in consideration of operational and capital recovery constraints. Appl Energy 2016;163:118-33. https://doi.org/10.1016/j.apenergy.2015.10.154.

[22] Andiappan V. State-Of-The-Art Review of Mathematical Optimisation Approaches for Synthesis of Energy Systems. Process Integr Optim Sustain 2017;1:165-88. https://doi.org/10.1007/s41660-017-00132.

[23] Rong A, Su Y. Polygeneration systems in buildings: A survey on optimization approaches. Energy Build 2017;151:439-54. https://doi.org/10.1016/j.enbuild.2017.06.077.

[24] Pina EA, Lozano MA, Serra LM. A multiperiod multiobjective framework for the synthesis of trigeneration systems in tertiary sector buildings. Int J Energy Res 2020;44:1140-66. https://doi.org/10.1002/er.5006.

[25] Ahn H, Rim D, Pavlak GS, Freihaut JD. Uncertainty analysis of energy and economic performances of hybrid solar photovoltaic and combined cooling, heating, and power (CCHP + PV) systems using a MonteCarlo method. Appl Energy 2019;255:113753. https://doi.org/10.1016/j.apenergy.2019.113753.

[26] Carvalho M, Lozano MA, Ramos J, Serra LM. Synthesis of Trigeneration Systems: Sensitivity Analyses and Resilience. Sci World J 2013;2013:1-16. https://doi.org/10.1155/2013/604852.

[27] Akbari K, Nasiri MM, Jolai F, Ghaderi SF. Optimal investment and unit sizing of distributed energy systems under uncertainty: A robust optimization approach. Energy Build 2014;85:275-86. https://doi.org/10.1016/j.enbuild.2014.09.009.

[28] Gimelli A, Muccillo M, Sannino R. Optimal design of modular cogeneration plants for hospital facilities and robustness evaluation of the results. Energy Convers Manag 2017;134:20-31. https://doi.org/10.1016/j.enconman.2016.12.027.

[29] Urbanucci L, Testi D. Optimal integrated sizing and operation of a CHP system with Monte Carlo risk analysis for long-term uncertainty in energy demands. Energy Convers Manag 2018;157:307-16. https://doi.org/10.1016/j.enconman.2017.12.008.

[30] Zhu X, Zhan X, Liang H, Zheng X, Qiu Y, Lin J, et al. The optimal design and operation strategy of renewable energy-CCHP coupled system applied in five building objects. Renew Energy 2020;146:270015. https://doi.org/10.1016/j.renene.2019.07.011.

[31] Thiem S, Danov V, Metzger M, Schäfer J, Hamacher T. Project-level multi-modal energy system design - Novel approach for considering detailed component models and example case study for airports. Energy 2017;133:691-709. https://doi.org/10.1016/j.energy.2017.05.159.

[32] Noussan M, Jarre M. Multicarrier energy systems: Optimization model based on real data and application to a case study. Int J Energy Res 2018;42:1338-51. https://doi.org/10.1002/er.3936.

[33] Ropenus S, Jacobsen HK, Schröder ST. Network regulation and support schemes - How policy interactions affect the integration of distributed generation. Renew Energy 2011;36:1949-56. https://doi.org/10.1016/j.renene.2010.12.015.

[34] De Boeck L, Van Asch S, De Bruecker P, Audenaert A. Comparison of support policies for residential photovoltaic systems in the major EU markets through investment profitability. Renew Energy 2016;87:42-53. https://doi.org/10.1016/j.renene.2015.09.063.

[35] Aquila G, Pamplona E de O, Queiroz AR de, Rotela Junior P, Fonseca MN. An overview of incentive policies for the expansion of renewable energy generation in electricity power systems and the Brazilian experience. Renew Sustain Energy Rev 2017;70:1090-8. https://doi.org/10.1016/j.rser.2016.12.013.

[36] Rickerson W, Laurent C, Jacobs D, Dietrich C, Hanley C. Feed-in tariffs as a policy instrument for promoting renewable energies and green economies in developing countries. Paris: 2012.

[37] IRENA, IEA, REN21. Renewable energy policies in a time of transition. 2020.

[38] Piacentino A, Gallea R, Cardona F, Lo Brano V, Ciulla G, Catrini P. Optimization of trigeneration systems by Mathematical Programming: Influence of plant scheme and boundary conditions. Energy Convers Manag 2015;104:100-14. https://doi.org/10.1016/j.enconman.2015.03.082.

[39] Camilo FM, Castro R, Almeida ME, Pires VF. Economic assessment of residential PV systems with self- 
consumption and storage in Portugal. Sol Energy 2017;150:353-62. https://doi.org/10.1016/j.solener.2017.04.062.

[40] Numbi BP, Malinga SJ. Optimal energy cost and economic analysis of a residential grid-interactive solar PV system- case of eThekwini municipality in South Africa. Appl Energy 2017;186:28-45. https://doi.org/10.1016/j.apenergy.2016.10.048.

[41] Cerino Abdin G, Noussan M. Electricity storage compared to net metering in residential PV applications. J Clean Prod 2018;176:175-86. https://doi.org/10.1016/j.jclepro.2017.12.132.

[42] Landini CL, de Mello Sant'Ana PH. Technical, economic, and regulatory analysis of the implementation of micro-cogeneration technology in the Brazilian manufacturing sector. Energy Effic 2017;10:957-71. https://doi.org/10.1007/s12053-016-9496-X.

[43] Lopes MM, Cobas VRM, Barros RM, Lora EES, dos Santos IFS. Energy potential using landfill biogas and solar photovoltaic system: a case study in Brazil. J Mater Cycles Waste Manag 2019;21:1587-601. https://doi.org/10.1007/s10163-019-00904-7.

[44] Cardemil JM, Starke AR, Colle S. Multi-objective optimization for reducing the auxiliary electric energy peak in low cost solar domestic hot-water heating systems in Brazil. Sol Energy 2018;163:486-96. https://doi.org/10.1016/j.solener.2018.01.008.

[45] Zheng CY, Wu JY, Zhai XQ, Wang RZ. Impacts of feed-in tariff policies on design and performance of CCHP system in different climate zones. Appl Energy 2016;175:168-79. https://doi.org/10.1016/j.apenergy.2016.05.005.

[46] Buonomano A, Calise F, Ferruzzi G, Vanoli L. A novel renewable polygeneration system for hospital buildings: Design, simulation and thermo-economic optimization. Appl Therm Eng 2014;67:43-60. https://doi.org/10.1016/j.applthermaleng.2014.03.008.

[47] Isa NM, Das HS, Tan CW, Yatim AHM, Lau KY. A techno-economic assessment of a combined heat and power photovoltaic/fuel cell/battery energy system in Malaysia hospital. Energy 2016;112:75-90. https://doi.org/10.1016/j.energy.2016.06.056.

[48] González-Mahecha RE, Lucena AFP, Szklo A, Ferreira P, Vaz AIF. Optimization model for evaluating on-site renewable technologies with storage in zero/nearly zero energy buildings. Energy Build 2018;172:505-16. https://doi.org/10.1016/j.enbuild.2018.04.027.

[49] Jiménez Navarro JP, Cejudo López JM, Connolly D. The effect of feed-in-tariff supporting schemes on the viability of a district heating and cooling production system. Energy 2017;134:438-48. https://doi.org/10.1016/j.energy.2017.05.174.

[50] Kang L, Yang J, An Q, Deng S, Zhao J, Wang H, et al. Effects of load following operational strategy on CCHP system with an auxiliary ground source heat pump considering carbon tax and electricity feed in tariff. Appl Energy 2017;194:454-66. https://doi.org/10.1016/j.apenergy.2016.07.017.

[51] Andersen AN, Østergaard PA. A method for assessing support schemes promoting flexibility at district energy plants. Appl Energy 2018;225:448-59. https://doi.org/10.1016/j.apenergy.2018.05.053.

[52] Lozano MA, Ramos JC, Serra LM. Cost optimization of the design of CHCP (combined heat, cooling and power) systems under legal constraints. Energy 2010;35:794-805. https://doi.org/10.1016/j.energy.2009.08.022.

[53] Schütz T, Schraven MH, Remy S, Granacher J, Kemetmüller D, Fuchs M, et al. Optimal design of energy conversion units for residential buildings considering German market conditions. Energy 2017;139:895915. https://doi.org/10.1016/j.energy.2017.08.024.

[54] Pinto ES, Serra LM, Lázaro A. Optimization of the design of polygeneration systems for the residential sector under different self-consumption regulations. Int $\mathrm{J}$ Energy Res 2020:er.5738. https://doi.org/10.1002/er.5738.

[55] Pina EA, Lozano MA, Ramos JC, Serra LM. Tackling thermal integration in the synthesis of polygeneration systems for buildings. Appl Energy 2020;269:115115. https://doi.org/10.1016/j.apenergy.2020.115115.

[56] Pina EA. Thermoeconomic and environmental synthesis and optimization of polygeneration systems supported with renewable energies and thermal energy storage applied to the residential-commercial sector. PhD Thesis - University of Zaragoza, Department of Mechanical Engineering, 2019.

[57] Biglia A, Caredda F V., Fabrizio E, Filippi M, Mandas N. Technical-economic feasibility of CHP systems in large hospitals through the Energy Hub method: The case of Cagliari AOB. Energy Build 2017;147:101-12. https://doi.org/10.1016/j.enbuild.2017.04.047.

[58] Gimelli A, Muccillo M. Optimization criteria for cogeneration systems: Multi-objective approach and 
application in an hospital facility. Appl Energy 2013;104:910-23. https://doi.org/10.1016/j.apenergy.2012.11.076.

[59] Midwest CHP Application Center. Combined Heat \& Power ( CHP ) Resource Guide for Hospital Applications. 2007.

[60] Salem Szklo A, Soares JB, Tolmasquim MT. Energy consumption indicators and CHP technical potential in the Brazilian hospital sector. Energy Convers Manag 2004;45:2075-91. https://doi.org/10.1016/j.enconman.2003.10.019.

[61] ANEEL. Normative Resolution 687/2015. 2015. https://doi.org/10.1017/CBO9781107415324.004.

[62] UNICAMP H. Hospital de Clínicas da UNICAMP 2021. https://hc.unicamp.br/ (accessed May 2, 2021).

[63] METEOTEST. METEONORM 2019. http://www.meteonorm.com/.

[64] COMGAS. Natural gas rates 2018. https://www.comgas.com.br/tarifas/.

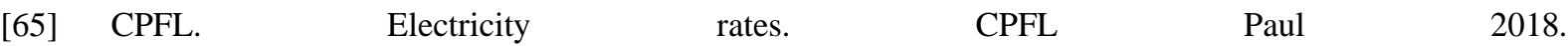
https://www.cpflempresas.com.br/institucional/tarifas.aspx?emp=CPFL.

[66] Delgado DB de M, Carvalho M, Junior LMC, Chacartegui R. Analysis of Biomass-fired Boilers in a Polygeneration System for a Hospital. Front Manag Res 2018;2:1-13. https://doi.org/10.22606/fmr.2018.21001.

[67] Rupp RF, Lamberts R. Relatório: Fatores de conversão de energia elétrica e térmica em energia primária e em emissões de dióxido de carbono a serem usados na etiquetagem de nível de eficiência energética de edificações 2017.

[68] MCTIC. Fatores de emissão da margem de operação pelo método da análise de despacho. [In Port 2020. http://www.mctic.gov.br/mctic/opencms/ciencia/SEPED/clima/textogeral/emissao_despacho.html (accessed May 21, 2020).

[69] ANEEL. Resolução Normativa nº 482 de 2012 da ANEEL. 2012.

[70] ANEEL. Resolução Normativa $n^{\circ} 687$ de 2015 da ANEEL. Aneel 2015:1-24. https://doi.org/10.1017/CBO9781107415324.004.

[71] Gucciardi Garcez C. Distributed electricity generation in Brazil: An analysis of policy context, design and impact. Util Policy 2017;49:104-15. https://doi.org/10.1016/j.jup.2017.06.005.

[72] Dranka GG, Ferreira P. Towards a smart grid power system in Brazil: Challenges and opportunities. Energy Policy 2020;136. https://doi.org/10.1016/j.enpol.2019.111033.

[73] ANEEL. Resolução Normativa nº 235 de 2006 da ANEEL 2006.

[74] Papoulias SA, Grossmann IE. A structural optimization approach in process synthesis-II. Comput Chem Eng 1983;7:707-21. https://doi.org/10.1016/0098-1354(83)85023-6.

[75] Duffie JA, Beckman WA. Solar Engineering of Thermal Processes. 4th ed. Wiley; 2013.

[76] SAM. System Advisor Model (SAM), version 2018.11.11. National Renewable Energy Laboratory (NREL); 2018.

[77] Wagner MJ, Gilman P. Technical manual for the SAM physical trough model, by National Renewable Energy Laboratory (NREL, U.S. Department of Energy). Natl Renew Energy Lab 2011;303:275-3000.

[78] Ramos JC. Optimización del diseño y operación de sistemas de cogeneración para el sector residencial comercial. PhD Thesis - University of Zaragoza, Department of Mechanical Engineering, 2012.

[79] Lazard. Lazard's Levelized Cost of Energy Analysis - 10. vol. 10.0. 2016.

[80] Ito M, Komoto K, Kurokawa K. A comparative LCA study on potential of very-large scale PV systems in Gobi desert. Conf Rec IEEE Photovolt Spec Conf 2009:729-32. https://doi.org/10.1109/PVSC.2009.5411180.

[81] Guadalfajara M. Economic and environmental analysis of central solar heating plants with seasonal storage for the residential sector 2016:262.

[82] Raluy RG, Serra LM, Guadalfajara M, Lozano MA. Life cycle assessment of central solar heating plants with seasonal storage. Energy Procedia 2014;48:966-76. https://doi.org/10.1016/j.egypro.2014.02.110.

[83] Kurup P, Turchi CS. Parabolic Trough Collector Cost Update for the System Advisor Model (SAM). Tech Rep NREL/TP-6A20-65228 Natl Renew Energy Lab 2015:1-40.

[84] Whitaker MB, Heath GA, Burkhardt JJ, Turchi CS. Life Cycle Assessment of a Power Tower Concentrating Solar Plant and the Impacts of Key Design Alternatives. Environ Sci Technol 2013;47:5896-903. https://doi.org/10.1021/es400821x.

[85] WEC. World Energy Resources: Solar 2016. 2016. https://doi.org/https://www.worldenergy.org/wp- 
content/uploads/2013/10/WER_2013_8_Solar_revised.pdf.

[86] Carvalho M. Thermoeconomic and environmental analyses for the synthesis of polygeneration systems in the residential-commercial sector. 2011.

[87] IEA. District Energy Systems in China 2017.

[88] Schrage L. Optimization modeling with LINGO. Lindo Systems, 1999.

[89] Energy Community Secretariat. Policy Guidelines by the Energy Community Secretariat on the Grid Integration of Prosumers. 2018.

[90] EREF. European Policy Advisory Paper. Brussels, March 2020: 2020.

[91] ANEEL. Regulatory Impact Analysis (Revisão das regras aplicáveis à micro e minigeração distribuída Resolução Normativa $n^{\circ}$ 482/2012). 2018.

[92] EPE. Brazilian energy balance 2020: Year 2019 [Balanço energético nacional 2020: Ano base 2019] 2020.

[93] Ferreira LRA, Otto RB, Silva FP, De Souza SNM, De Souza SS, Ando Junior OH. Review of the energy potential of the residual biomass for the distributed generation in Brazil. Renew Sustain Energy Rev 2018;94:440-55. https://doi.org/10.1016/j.rser.2018.06.034.

[94] Freitas FF, De Souza SS, Ferreira LRA, Otto RB, Alessio FJ, De Souza SNM, et al. The Brazilian market of distributed biogas generation: Overview, technological development and case study. Renew Sustain Energy Rev 2019;101:146-57. https://doi.org/10.1016/j.rser.2018.11.007. 